\title{
RESEARCH
}

\section{Generation and Analysis of 280,000 Human Expressed Sequence Tags}

\author{
LaDeana Hillier, ${ }^{1,4}$ Greg Lennon, ${ }^{2}$ Michael Becker, ${ }^{1}$ \\ M. Fatima Bonaldo, ${ }^{3}$ Brandi Chiapelli, ${ }^{1}$ Stephanie Chissoe, ${ }^{1}$ \\ Nicole Dietrich, ${ }^{1}$ Treasa DuBuque, ${ }^{1}$ Anthony Favello, ${ }^{1}$ Warren Gish, ${ }^{1}$ \\ Maria Hawkins, ${ }^{1}$ Monica Hultman, ${ }^{1}$ Tamara Kucaba, ${ }^{1}$ Michelle Lacy, ${ }^{1}$ \\ Maithao Le, ${ }^{1}$ Nha Le, ${ }^{1}$ Elaine Mardis, ${ }^{1}$ Bradley Moore, ${ }^{1}$ Matthew Morris, ${ }^{1}$ \\ Jeremy Parsons, ${ }^{1}$ Christa Prange, ${ }^{3}$ Lisa Rifkin, ${ }^{1}$ Theresa Rohlfing, ${ }^{1}$ \\ Kurt Schellenberg, ${ }^{1}$ M. Bento Soares, ${ }^{2}$ Fang Tan, ${ }^{1}$ Jean Thierry-Meg, ${ }^{1}$ \\ Evanne Trevaskis, ${ }^{1}$ Karen Underwood, ${ }^{1}$ Patricia Wohldman, ${ }^{1}$ \\ Robert Waterston, ${ }^{1}$ Richard Wilson, ${ }^{1}$ and Marco Marra ${ }^{1}$
}

\footnotetext{
${ }^{1}$ Genome Sequencing Center, Washington University School of Medicine, St. Louis, Missouri 63108;

${ }^{2}$ Human Genome Center, Lawrence Livermore National Laboratories, Livermore, California 94550;

${ }^{3}$ Department of Psychiatry, College of Physicians and Surgeons of Columbia University, and the New York State Psychiatric Institute, New York, New York 10032
}

We report the generation of 319,311 single-pass sequencing reactions (known as expressed sequence tags, or ESTs) obtained from the $5^{\prime}$ and $3^{\prime}$ ends of 194,031 human cDNA clones. Our goal has been to obtain tag sequences from many different genes and to deposit these in the publicly accessible Data Base for Expressed Sequence Tags. Highly efficient automatic screening of the data allows deposition of the annotated sequences without delay. Sequences have been generated from 26 oligo(dT) primed directionally cloned libraries, of which 18 were normalized. The libraries were constructed using mRNA isolated from 17 different tissues representing three developmental states. Comparisons of a subset of our data with nonredundant human mRNA and protein data bases show that the ESTs represent many known sequences and contain many that are novel. Analysis of protein families using Hidden Markov Models confirms this observation and supports the contention that although normalization reduces significantly the relative abundance of redundant cDNA clones, it does not result in the complete removal of members of gene families.

The recovery of single-pass sequences (known as expressed sequence tags, or ESTs) from random cDNA clones has been pursued as a relatively inexpensive and rapid means to access many of the expressed genes of an organism (Milner and Sutcliffe 1983; Putney et al. 1983). With the advent of high-throughput sequencing technology and an increased interest in genome-wide studies, it became clear that ESTs could be generated in sufficient numbers to provide a rapid means of gene discovery (Adams et al. 1991, 1995; Khan et al. 1992; McCombie et al. 1992; Waterson et al. 1992; Newman 1994; Sasaki et al. 1994; Houl-

${ }^{4}$ Corresponding author.

E-MAIL Ihillier@watson.wustl.edu; FAX (314) 286-1810. gatte et al. 1995), especially for those searching for human disease genes or constructing physical maps of the human genome. ESTs also have proven valuable for studying temporal and spatial expression patterns (Matsubara and Okubo 1993) and could be used to construct a genomewide STS based transcript map (Wilcox et al. 1991). In spite of their many uses, the number of ESTs in the public data bases totaled only 38,594 by December 1994.

ESTs have been used extensively in genomic sequencing projects. For example, the comparison of end sequences from Caenorhabditis elegans cDNAs (Y. Kohara, unpubl.; McCombie et al. 1992; Waterston et al. 1992) with genomic sequence has enhanced substantially our ability to 


\section{HILLIER ET AL.}

identify genes (R. Waterston et al., in prep.; Wilson et al. 1994). ESTs both verify that predicted genes are transcribed and identify splice sites. Further, ESTs have been essential in the analysis of complex gene structures such as long introns, alternative splice sites, operons, and overlapping transcription units. In addition, it has become clear that ESTs need not be lengthy or of high accuracy to be of use; they need only be long enough to specify a unique sequence in the genome, and accurate enough to allow recognition of similarity by commonly used computer programs [e.g., BLAST (Altschul et al. 1990) or FASTA (Pearson and Lipman 1988)]. With the initiation of a coordinated effort to obtain the sequence of the human genome, human ESTs will assume a similar role in enhancing the interpretation and annotation of the genomic sequence. ESTs will also contribute to the development of sequenceready maps.

The potential for early gene discovery combined with the long-term value of ESTs for analysis of the human genome prompted us, in cooperation with Merck (Aaronson et al., this issue) and the IMAGE Consortium (Lennon et al. 1996), to initiate a large-scale human EST sequencing effort to expand the scope of the publicly available EST data and thereby enhance its utility.

\section{RESULTS}

We have submitted to the Data Base for Expressed Sequence Tags (dbEST) 319,311 ESTs from 444,692 attempted sequences $(194,031$ cDNA clones) for an overall success rate of $72 \%$ calculated after removal of poor quality, bacterial, mitochondrial, and vector sequences. The analyses presented here were performed on 280,223 ESTs generated from the 173,620 clones sequenced as of April 1, 1996. These sequences were from 22 libraries (15 normalized and 7 nonnormalized) representing 12 different tissues and 3 developmental states (fetus, infant, and adult). Two of the normalized libraries were prepared from RNA isolated from diseased tissue. The details of the construction of the normalized libraries and the advantages offered by them are presented by Bonaldo et al. (this issue). All of the sequences were obtained from oligo(dT) primed directionally cloned cDNAs. An approximately equal number of $5^{\prime}$ and $3^{\prime}$ ends $(140,532$ and 139,691 sequences, respectively) were sequenced. A list of the libraries sampled and the numbers of sequences obtained from each library are presented in Table 1.

The decision to generate ESTs preferentially from certain libraries was based on measures of library quality and library complexity (see below) as well as the general suitability of the library for large-scale sequencing. Suitability for sequencing initially was determined largely by trial and error. We found that cloning vectors that had M13 primer annealing sites tended to yield higherquality sequence. Furthermore, M13 primers yielded favorable results over a broad range of DNA concentrations, which allowed sequencing without quantitation of individual samples. This was in sharp contrast to other dye primers that yielded high-quality sequence over narrower ranges in DNA concentrations. An additional factor in choice of libraries was the bacterial cell type in which the library was propagated. Best results were achieved with DH10B (Life Technologies).

\section{Identification of Contaminating Sequences}

To maximize the number of genes surveyed we monitored closely the data from each library, sampling extensively from only those libraries that were amenable to sequencing, of high quality, and continuing to yield a high fraction (greater than $40 \%$ ) of novel sequences. To assay library quality, EST sequences were screened against data bases of bacterial sequences, mitochondrial sequences, and vector sequences. The levels of these contaminating sequences (or "nontechnical failures") are shown for each library in Figure 1. Libraries containing $>2 \%$ nonrecombinant plasmids, $4 \%$ bacterial sequences, or $7 \%$ mitochondrial sequences were not selected for extensive sampling. In general, the normalized libraries (Bonaldo et al., this issue) showed comparatively low levels of nontechnical failures, with essentially no nonrecombinant plasmids and low levels of bacterial sequences. All of the libraries contained mitochondrial sequences, ranging from a high of $16 \%$ of ESTs (N2b5HB55Y) to a low of less than $1 \%$ of ESTs (2NbHP8to9W). Sequences considered to be nontechnical failures were not submitted to dbEST but are available upon request.

\section{Assaying Library Complexity}

Since all libraries were oligo(dT) primed from 
Table 1. cDNA Libraries: Attempted and Successful Sequences as of April 1, 1996

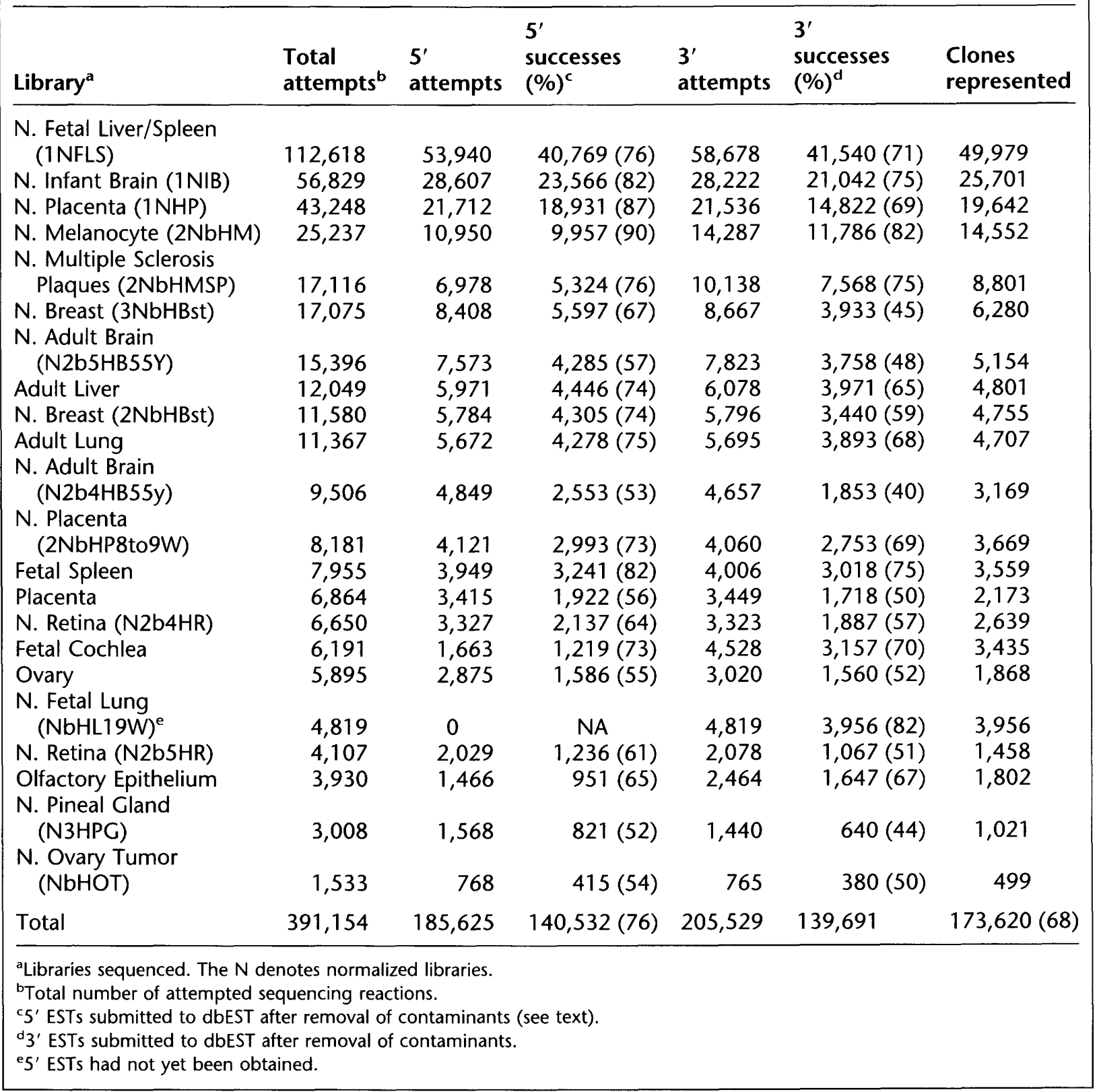

poly(A) tracts, 3' ESTs were considered likely to provide the $3^{\prime}$ termini of genes. To examine library complexity we performed intralibrary comparisons of all successful 3' ESTs. ESTs that had significant matches to other ESTs within the library were grouped into families, and those that could not be grouped into families were considered "singletons" (see Fig. 2 for examples). Those libraries exhibiting higher proportions of singletons were considered to be of higher complexity, thus warranting more extensive sampling.
To generate an estimate of the diversity of the entire set of ESTs we performed a similar analysis, first combining the highest quality $3^{\prime}$ EST data from all libraries and then grouping the ESTs as described in Methods. This analysis placed 81,884 of a possible $111,1893^{\prime}$ ESTs into 14,850 groups. The remaining $29,4853^{\prime}$ ESTs ( $27 \%$ of the total) could not be grouped and therefore were classified as singletons (Table 2). Thus, there are $44,335(14,850+29,485)$ distinct 3' EST groups. Others using different clustering 
HILLIER EI AL.

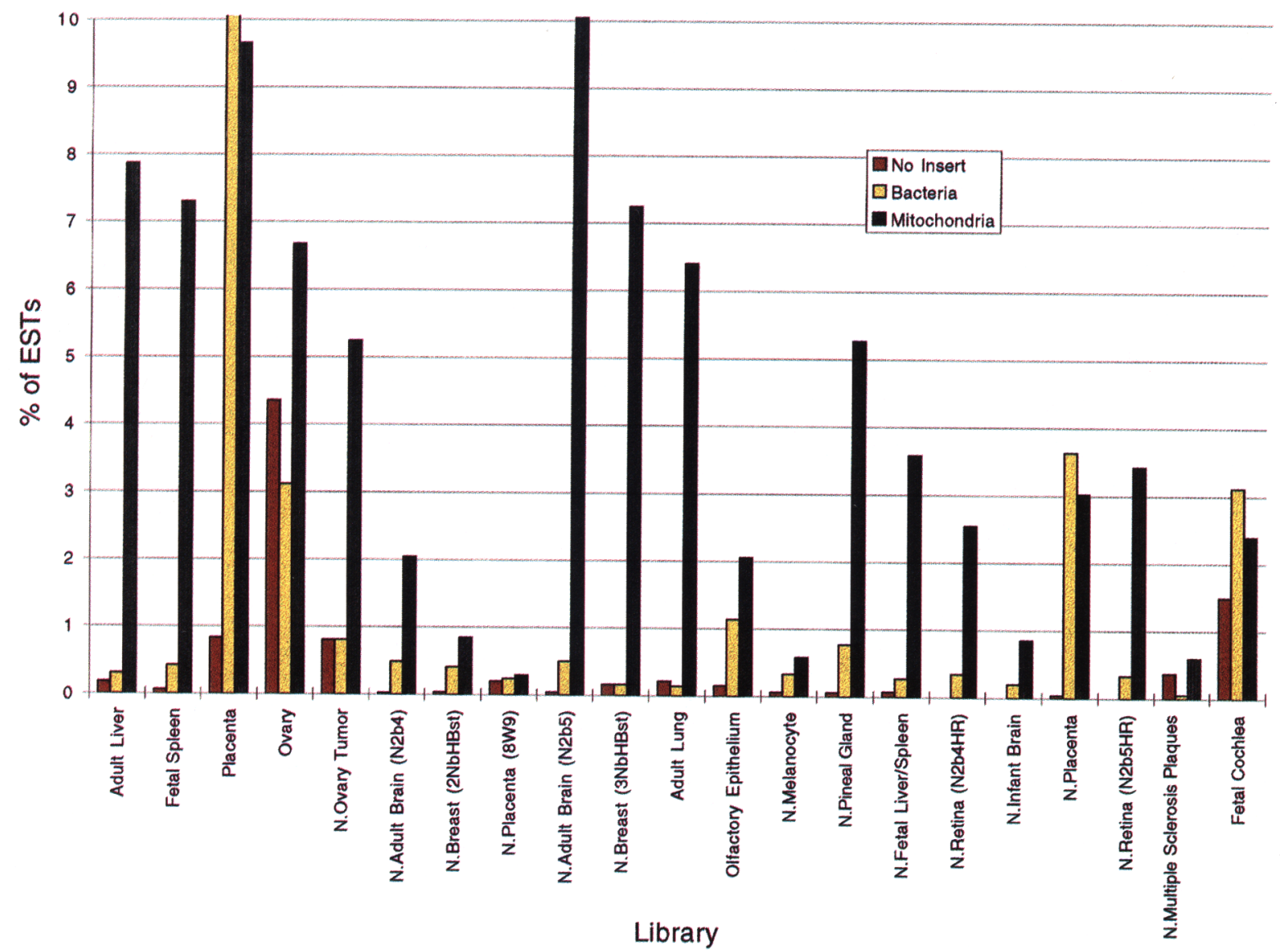

Figure 1 Proportion of ESTs classified as vector, mitochondrial, and bacterial from the normalized (N) and non-normalized libraries. For the normalized retina libraries and the normalized infant brain library, the percentage of nonrecombinant plasmids was less than $0.1 \%$. For the $\mathrm{N}$. Fetal Lung (NbHL19W) library (not shown), the percentages of nonrecombinant plasmid, bacterial, and mitochondrial clones were less than $0.3 \%$. The mitochondrial contamination in the N2b5 adult brain library (16\%) and the bacterial contamination in the placenta library (20\%) exceeded the range plotted on this graph. The sequences determined to be from nonrecombinant plasmids or of bacterial or mitochondrial origin were not submitted to the public database but are available on request.

algorithms have generated similar estimates (G. Schuler and M. Boguski, in prep.; Aaronson et al., this issue). This number is a rough estimate of the number of distinct genes identified by our EST data. However, this figure could be considered a maximal estimate because it depends heavily on the clustering parameters as well as the frequency of reversed clones, internal or nonspecific priming, and alternatively spliced $3^{\prime}$ exons. To estimate the fractions of these artifacts in our data set the following analyses were performed.

\section{Estimating the Frequency of Nonspecific Priming}

To generate estimates of the frequency of nonspecific priming we compared 3' ESTs with the nonredundant human mRNA data base. Highly significant EST matches were evaluated according to the location of the matched bases in the cognate mRNA and whether another EST was found to match at that position. Examining the entire data set, we found that 27,919 3' ESTs matched sequences in the human mRNA data base in the correct orientation. Of these, 21,487 (77\%) of the ESTs matched the annotated 3 ' ends of mRNAs. An additional $21.5 \%(6009 / 27,919)$ of the ESTs matched sequences internal to mRNAs and were confirmed by at least one other EST matching at the same position. The remaining 423 ESTs (1.5\%) matched sequences internal to mRNAs but were not confirmed by another EST hit to the same region. These latter ESTs represent 
GENERATION AND ANALYSIS OF 280,000 HUMAN ESTS

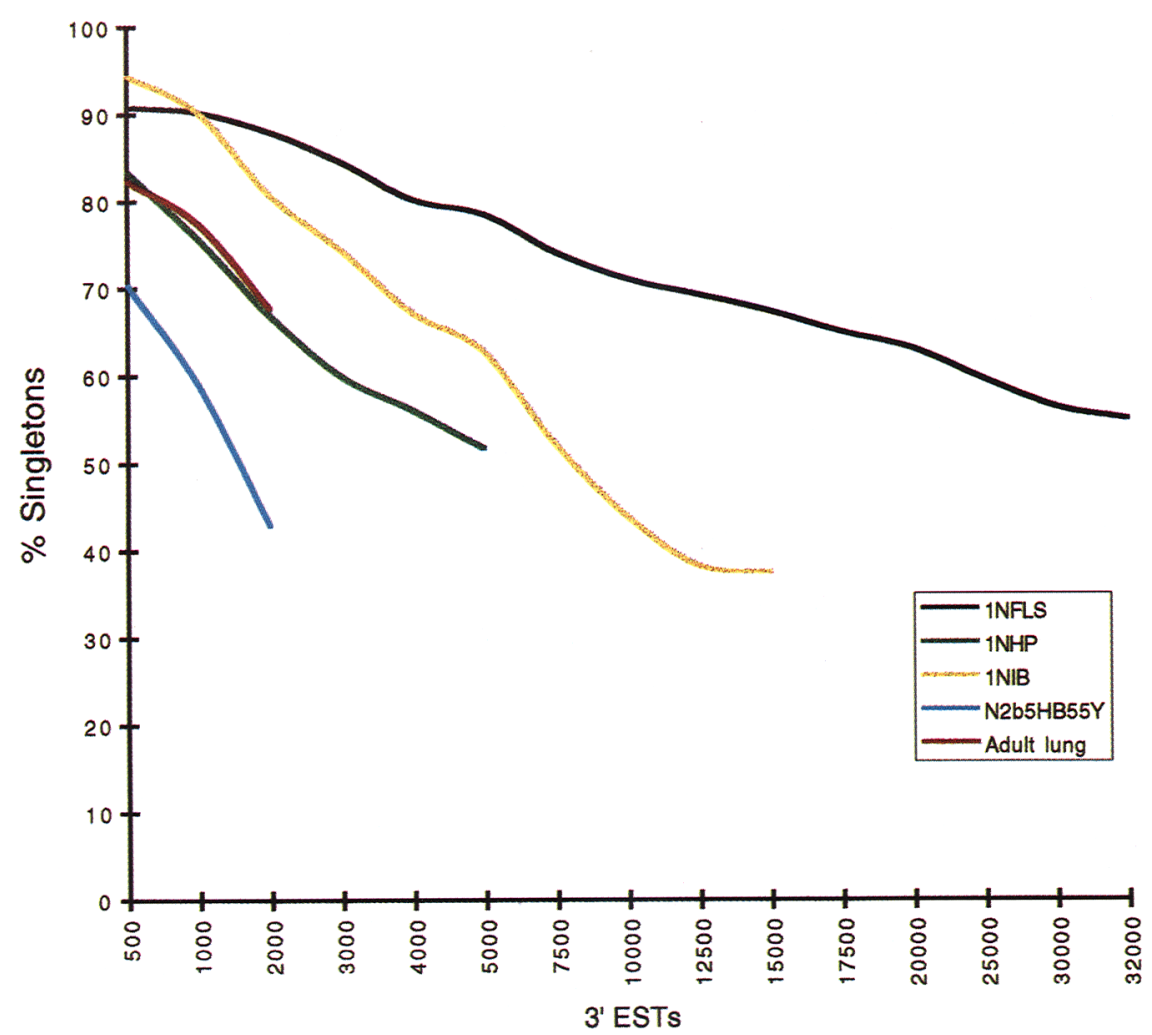

Figure 2 The percent of novel intralibrary $3^{\prime}$ ESTs (singletons) as a function of the number of successful $3^{\prime}$ ESTs is shown. The slopes of the curves indicate the rate at which the fraction of singletons within individual libraries declined. For example, a shallow slope (as seen for the 1NFLS library) indicates that the library continued to be a rich source of new information even after extensive sampling. These data show that even among normalized libraries there are different rates of discovery of novel sequences. The "best" non-normalized library (adult lung) is shown for comparison.

the maximal proportion of nonspecific priming events and may well include infrequent splicing events that have resulted in alternative $3^{\prime}$ exons in the mature mRNA. Data are given for each of the libraries in Table 3.

\section{Estimating the Frequency of Inverted Clones}

A substantial fraction of inverted clones would inflate estimates of library complexity. The cDNA inserts could be inverted due to failures in the directional cloning procedure. Alternatively, inserts could appear to be inverted as a result of human-induced errors in EST nomenclature during the sample handling, data tracking, or analysis phases of the sequencing process. To generate an estimate of the frequency of reversed clones the $3^{\prime}$ EST data set was compared with the human
mRNA data base. In addition to the $27,9193^{\prime}$ ESTs that matched in the correct orientation, there were $1,8633^{\prime}$ ESTs that matched human mRNA data-base sequences in inverted orientation. This represents $6.25 \%$ of the total number of ESTs matching a human mRNA sequence in either orientation. Additional experimentation will be required to determine whether these represent artifacts or overlapping convergent transcripts.

To determine the fraction of clones perceived to be reversed because of human error, we searched for redundant EST hits on the wrong strand. Multiple independently derived hits to the same region of an mRNA were unlikely to reflect human error that would be nonsystematic in our data flow paradigm. Further, such hits would support the notion that the perceived reversal was not attributable to a failure in the directional cloning procedure. Of the 1,863 ESTs that hit on the wrong strand, 1327 (71\%) were "confirmed" by at least one other hit to the same region of their cognate mRNA, and 536 ESTs (29\%) were not (Table 4). Thus the clone reversal rate due to human error can be estimated to be no more than the number of unconfirmed ESTs divided by the number of ESTs found to match the mRNA in either orientation $(1.8 \%)$.

\section{Estimating the Frequency of Chimeric Clones}

As an additional metric of library quality the incidence of chimeric cDNA clones was estimated. Chimeric clones could arise during the cDNA cloning procedure as a result of the artifactual fusion of cDNAs derived from genes unlinked in the genome. Alternatively, clones perceived as chimeric could arise because of errors in sample handling. For example, an error in postelectro- 
HILLIER ET AL.

\begin{tabular}{|lrll|}
\hline Table 2. Clustering of 3' ESTs & & & \\
\hline Library & 3' $^{\prime}$ EST s $^{\mathbf{a}}$ & Singletons $^{\mathbf{b}}$ & \% singletons \\
\hline N. Fetal Liver/Spleen (1NFLS) & 34,156 & 12,578 & 36.8 \\
N. Infant Brain (1NIB) & 17,282 & 3,003 & 17.4 \\
N. Placenta (1NHP) & 11,751 & 2,061 & 17.5 \\
N. Melanocyte (2NbHM) & 10,563 & 2,113 & 20.0 \\
N. Multiple Sclerosis Plaques (2NbHMSP) & 6,148 & 1,714 & 27.9 \\
N. Breast (3NbHBst) & 2,652 & 462 & 17.4 \\
N. Adult Brain (N2b5HB55Y) & 2,715 & 414 & 15.3 \\
Adult Liver & 2,736 & 583 & 21.3 \\
N. Breast (2NbHBst) & 2,540 & 517 & 20.4 \\
Adult Lung & 2,527 & 840 & 33.2 \\
N. Adult Brain (N2b4HB55Y) & 1,338 & 231 & 17.3 \\
N. Placenta (2NbHP8to9W) & 2,526 & 563 & 22.3 \\
Fetal Spleen & 2,143 & 644 & 30.1 \\
Placenta & 1,199 & 254 & 21.2 \\
N. Retina (N2b4HR) & 1,601 & 779 & 48.7 \\
Fetal Cochlea & 2,581 & 696 & 27.0 \\
Ovary & 916 & 577 & 63.0 \\
N. Fetal Lung (NbHL19W) & 3,184 & 578 & 18.2 \\
N. Retina (N2b5HR) & 776 & 265 & 34.2 \\
Olfactory Epithelium & 1,079 & 293 & 27.2 \\
N. Pineal Gland (N3HPG) & 415 & 196 & 47.2 \\
N. Ovary Tumor (NbHOT) & 361 & 124 & 34.4 \\
Total & 111,189 & 29,485 & 26.5 \\
\hline aNumber of high-quality ESTs included in the clustering analysis (see Methods). & \\
bNumber of ESTs that were unique among the combined set of high-quality 3' ESTs from all libraries. &
\end{tabular}

phoresis lane tracking could result in transposition of EST identities for all ESTs on the gel distal to the incorrectly tracked lane. In this case, the clones corresponding to these ESTs would be perceived as chimeric, since their $5^{\prime}$ and $3^{\prime}$ ESTs would derive from different mRNAs.

We compared our entire EST data set with the human mRNA data base and identified those $\mathrm{cD}$ NAs that had 5' and 3' ESTs that matched the same mRNA. We also identified those cDNAs that had 3' EST hits to a human mRNA sequence but failed to exhibit a 5' EST hit to that sequence as candidate chimeric clones. Alternatively, these 5' ESTs might be derived from cDNAs that are longer than the human mRNA data-base sequence. Another possibility is that these 5' ESTs identify alternatively spliced mRNA variants not included in the human mRNA data base. Elucidation of the exact nature of the candidate chimeric clones must await the collection of additional cDNA and genomic sequence data. However, the frequency of these events can provide a maximal estimate of the frequency of chimeras.
We identified 5399 cDNA clones that had both $5^{\prime}$ and $3^{\prime}$ EST hits to a human mRNA sequence. An additional 57 cDNAs had 3' EST hits to a human mRNA sequence but no $5^{\prime}$ EST hit to that mRNA, suggesting a frequency of chimeras no greater than $1.04 \%$ for the entire data set. Data for each library are presented in Table 5.

\section{Estimating the Frequency of ESTs Derived from Intronic and Intergenic Sequences}

To obtain an estimate of the number of cDNA clones derived from intronic or intergenic sequences we compared our 5' and 3' EST data with 8.2 megabases of human genomic DNA sequence culled from GenBank. We found 755 cDNA clones that had both $5^{\prime}$ and $3^{\prime}$ EST matches to the genomic sequence. To identify all the cDNAs deriving from mature mRNAs we performed the following analysis on these clones. First, we determined whether there existed other ESTs that confirmed the 5' or 3' EST match. We assumed that redundant cDNAs derived from nonspecifically 


\begin{tabular}{|c|c|c|c|}
\hline Library & $\begin{array}{l}\text { Matches } 3^{\prime} \text { end } \\
\text { or confirmed }\end{array}$ & $\begin{array}{l}\text { Internal and } \\
\text { unconfirmed }\end{array}$ & $\%$ unconfirmed \\
\hline N. Fetal Liver/Spleen (1NFLS) & 7429 & 151 & 2.00 \\
\hline N. Infant Brain (1NIB) & 2851 & 45 & 1.60 \\
\hline N. Placenta (1NHP) & 3051 & 26 & 0.90 \\
\hline N. Melanocyte (2NbHM) & 2337 & 43 & 1.80 \\
\hline \multicolumn{4}{|l|}{ N. Multiple Sclerosis Plaques } \\
\hline (2NbHMSP) & 944 & 20 & 2.10 \\
\hline N. Breast (3NbHBst) & 1149 & 11 & 1.00 \\
\hline N. Adult Brain (N2b5HB55Y) & 834 & 9 & 1.08 \\
\hline Adult Liver & 1818 & 17 & 0.93 \\
\hline N. Breast (2NbHBst) & 872 & 13 & 1.49 \\
\hline Adult Lung & 863 & 12 & 1.39 \\
\hline N. Adult Brain (N2b4HB55Y) & 362 & 3 & 0.83 \\
\hline N. Placenta (2NbHP8to9W) & 591 & 8 & 1.35 \\
\hline Fetal Spleen & 850 & 9 & 1.06 \\
\hline Placenta & 590 & 5 & 0.85 \\
\hline N. Retina (N2b4HR) & 227 & 8 & 3.50 \\
\hline Fetal Cochlea & 717 & 4 & 0.56 \\
\hline Ovary & 300 & 6 & 2.00 \\
\hline N. Fetal Lung (NbHL19W) & 962 & 19 & 1.98 \\
\hline N. Retina (N2b5HR) & 112 & 5 & 4.46 \\
\hline Olfactory Epithelium & 438 & 3 & 0.68 \\
\hline N. Pineal Gland (N3HPG) & 85 & 4 & 4.70 \\
\hline N. Ovary Tumor (NbHOT) & 114 & 2 & 1.75 \\
\hline Total & 27,496 & 423 & 1.54 \\
\hline
\end{tabular}

transcribed genomic DNA would be present at low frequencies. Therefore, two or more ESTs that matched the same nucleotides in the genomic DNA were considered to identify an mRNA as were ESTs that had a match that indicated the presence of an intron in the genomic sequence. Finally, we identified those ESTs that matched genomic sequence annotated as coding. This left $17(2.25 \%)$ of the original 755 cDNAs that were potentially derived from intronic or intergenic sequence. Of these 17 clones, 13 had ESTs that matched incompletely annotated GenBank sequences, which made verification of the origin of these clones impossible. Each of the remaining four clones $(0.53 \%)$ matched a region of an annotated GenBank sequence that was not labeled as coding. Any of these 17 cDNAs could be derived from unannotated exons or nonintron- spanning untranslated regions (UTRs) of mRNAs. This low frequency of potential contaminants would not significantly alter our estimates of library complexity or have generally negative implications for the prediction of transcription units in genomic sequence.

\section{Measuring the Frequency of Discrepancies}

ESTs are unedited single-pass sequences and are thus prone to error. This error has different components, including base miscalling and errors in lane tracking. Errors in called bases are observed in sequences considered to be of high quality, suggesting that automated base calling itself is an error-prone process. Estimates of the frequency of errors introduced by the ABI base-calling software have been reported (Sulston et al. 1992). 


\section{HILLIER ET AL.}

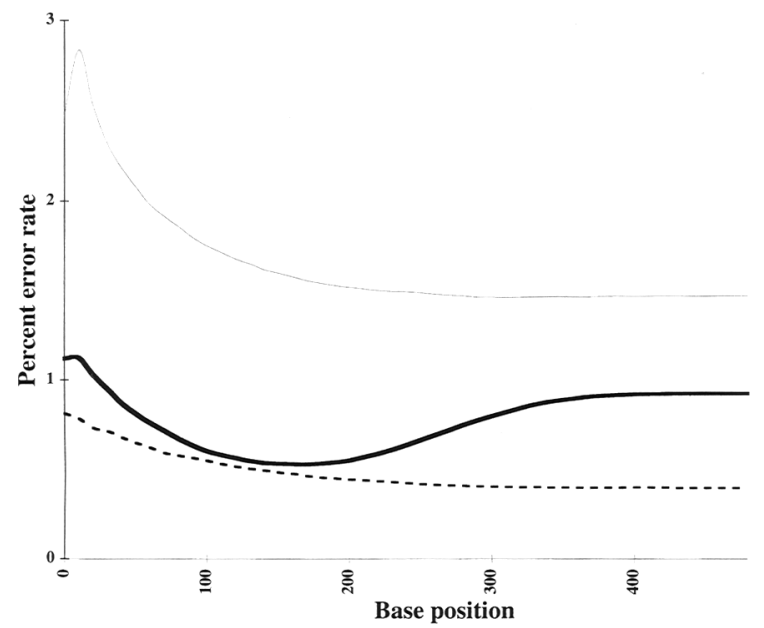

Figure 3 The percent substitution (thin line), insertion (heavy line), and deletion (dotted line) rates for $60005^{\prime}$ and 3' EST sequences with respect to their corresponding human mRNAs. Errors were not examined individually and therefore do not account for sequence polymorphisms, alternative splicing events, or errors in the human mRNA data-base sequences. Since the comparisons were performed on the portion of the submitted sequences annotated as "high quality," the error rates do not increase significantly toward the end of the sequences. These data indicate that the highest quality portion of the EST sequence is between bases 100 and 300 .

Thus, ESTs are best suited for purposes that do not rely on error-free data.

We estimated the frequency of errors in our EST data by performing alignments of $5^{\prime}$ and $3^{\prime}$ ESTs to sequences from a data base of nonredundant human mRNAs and identifying discrepancies between the sequences. The discrepancies were categorized as substitutions [mismatches including those involving ambiguous base calls ("Ns")], deletions (a base missing in the EST but present in the mRNA sequence), or insertions (a base present in the EST but not in the mRNA). We then calculated the average frequency of each of the discrepancies per human mRNA-EST alignment for 5' ESTs and 3' ESTs for regions annotated as high-quality in the dbEST entry. Data resulting from these calculations are shown in Table 6. These frequencies represent maximal estimates of error in the EST data, because they do not account for sequence polymorphisms, alternative splicing events, or errors in the human mRNA data-base sequences. Error rates for the entire length of the submitted EST that contained additional lower-quality sequences increase by about $1 \%$. Distributions of those error rates across sequences show that for regions of the sequence annotated as high-quality, $94 \%$ of the $5^{\prime}$ ESTs had a substitution rate of $5 \%$ or less and $83 \%$ had a substitution rate of $2 \%$ or less. For the highquality region of the $3^{\prime}$ ESTs, $93 \%$ had a substitution rate of $5 \%$ or less and $73 \%$ had a substitution rate of $2 \%$ or less. Average read lengths were 242 bases for the high-quality portions of the read and 364 for the entire submitted read. As shown in Figure 3, substitution error rates are highest at the beginning of the read; because the reads are trimmed based on quality, the error rates do not deteriorate significantly near the end of the read. Insertion errors are also higher at the 5 ' end of the read, reach a minimum around 150 bases, and then increase after moving past about 250 bases. The region of the EST between 100 and 300 bases is the most accurate portion of the sequence.

\section{What Fraction of Public Domain Sequences Are Hit by ESTs?}

To assay the extent of overlap between our ESTs and other public sequence data we used BLAST programs to compare the ESTs with a number of data bases. These included the human mRNA data base described above, a version of SWISSPROT (Bairoch and Boeckman 1994; release 32) containing only human protein sequences, and a data base of all publicly accessible yeast proteins. In addition, we used a sensitive Hidden Markov Model (HMM) analysis (Krogh et al. 1994; Eddy et al. 1995) to examine the representation of 171 different protein families in the EST data. We consider each of these analyses below.

The proportion of human mRNA data-base sequences hit by an EST was calculated for BLASTN2 $P$ values ranging from $10^{-9}$ to $10^{-209}$. With decreasing $P$ values, the fraction of the sequences in the data base exhibiting a match of at most that $P$ value decreased as expected (Fig. 4). Of interest is the large fraction of mRNA sequences represented in the ESTs. For example, a $P$ value of $10^{-109}$ in this analysis corresponds to a BLASTN2 score of approximately 1000. Using our selected parameters where a match receives a +5 score and a mismatch receives a -11 score, a cumulative score of 1000 can be achieved by two sequences having $100 \%$ identity over a span of 200 bases. Approximately $72 \%$ of the 4169 human mRNA sequences were similar to 35,968 dif- 
Table 4. Estimating the Frequency of Inverted Clones

\begin{tabular}{|c|c|c|c|c|c|}
\hline Library & $\begin{array}{l}\text { Total 3' } \\
\text { EST hits }\end{array}$ & $\begin{array}{l}\text { Coding } \\
\text { strand hits } \\
\text { (inverted } \\
\text { clones) }^{b}\end{array}$ & $\begin{array}{l}\% \text { coding } \\
\text { strand hits }\end{array}$ & $\begin{array}{l}\text { Confirmed } \\
\text { coding strand } \\
\text { hits }(\%)^{c}\end{array}$ & $\begin{array}{l}\text { \% unconfirmed } \\
\text { coding strand } \\
\text { hits }^{\text {d }}\end{array}$ \\
\hline N. Fetal Liver/Spleen (1NFLS) & 7949 & 351 & 4.42 & $222(63)$ & 1.6 \\
\hline N. Infant Brain (1NIB) & 2966 & 58 & 1.96 & $38(66)$ & 0.67 \\
\hline N. Placenta (1NHP) & 3429 & 340 & 9.92 & 251 (74) & 2.6 \\
\hline N. Melanocyte (2NbHM) & 2640 & 255 & 9.66 & $226(89)$ & 1.1 \\
\hline \multicolumn{6}{|l|}{ N. Multiple Sclerosis Plaques } \\
\hline (2NbHMSP) & 1025 & 60 & 5.85 & $39(65)$ & 2.05 \\
\hline N. Breast (3NbHBst) & 1287 & 122 & 9.48 & $102(84)$ & 1.55 \\
\hline N. Adult Brain (N2b5HB55Y) & 961 & 114 & 11.86 & 74 (65) & 4.16 \\
\hline Adult Liver & 1850 & 12 & 0.65 & $7(58)$ & 0.27 \\
\hline N. Breast (2NbHBst) & 981 & 95 & 9.68 & 75 (79) & 2.04 \\
\hline Adult Lung & 922 & 47 & 5.1 & $19(40)$ & 3.04 \\
\hline N. Adult Brain (N2b4HB55Y) & 434 & 67 & 15.44 & 58 (87) & 2.07 \\
\hline N. Placenta (2NbHP8to9W) & 668 & 67 & 10.03 & 46 (69) & 3.14 \\
\hline Fetal Spleen & 870 & 9 & 1.03 & $2(22)$ & 0.8 \\
\hline Placenta & 606 & 11 & 1.82 & $4(36)$ & 1.15 \\
\hline N. Retina (N2b4HR) & 294 & 59 & 20.07 & 44 (75) & 5.1 \\
\hline Fetal Cochlea & 742 & 21 & 2.83 & 7 (33) & 1.89 \\
\hline Ovary & 327 & 21 & 6.42 & $8(38)$ & 3.98 \\
\hline N. Fetal Lung (NbHL19W) & 1074 & 92 & 8.57 & $62(67)$ & 2.79 \\
\hline N. Retina (N2b5HR) & 151 & 34 & 22.52 & $25(74)$ & 5.96 \\
\hline Olfactory Epithelium & 448 & 7 & 1.56 & $4 \quad(57)$ & 0.67 \\
\hline N. Pineal Gland (N3HPG) & 105 & 16 & 15.24 & $9 \quad(56)$ & 6.67 \\
\hline N. Ovary Tumor (NbHOT) & 121 & 5 & 4.13 & $5(100)$ & 0 \\
\hline Total & 29,850 & 1863 & 6.24 & 1327 (71) & 1.8 \\
\hline
\end{tabular}

ferent ESTs at $P$ values of $10^{-109}$ or better, indicating substantial overlap between our EST data and the human mRNA data base. In a similar fashion we compared our data with a humanonly version of the SWISS-PROT (release 32) protein data base of 3281 sequences using TBLASTN (Fig. 4; Methods). Again, we found evidence for substantial overlap between the EST data and the human-only version of SWISS-PROT. Approximately $51 \%$ of the 3281 sequences in this data base were hit by ESTs at $P$ values of $10^{-59}$ or of higher significance.

Similarly, we compared our EST data with a set of all of the publicly available 8269 yeast proteins. While the yeast data set is reportedly nonredundant, some redundancy clearly remained given that there are approximately 6000 genes in the yeast genome (Dujon 1996; Johnston 1996). Strongly conserved sequences were identified between the yeast and EST data sets (Fig. 4) in spite of the limited length and accuracy of the ESTs. We found that 89 yeast proteins were similar to 37 different translated ESTs (considering only the EST with the highest degree of similarity) at TBLASTN $P$ values of $10^{-79}$ or better. Closer inspection of the hits revealed 24 ribosomal proteins, 12 heat shock proteins, 5 tubulins, and 2 actins (Table 7). These proteins are among the most strongly conserved across evolution; their inclusion here is not surprising. The presence of highly similar genes in model organisms like yeast offers the possibility of detailed functional characterization (see, e.g., Tugendreich et al. 1993). 
HILLIER ET AL.

\begin{tabular}{|c|c|c|c|}
\hline Library & 5'/3' EST pairs ${ }^{a}$ & Potential chimeras $^{b}$ & $\%$ chimeras \\
\hline N. Fetal Liver/Spleen (1NFLS) & 1528 & 12 & 0.78 \\
\hline N. Infant Brain (1 NIB) & 408 & 9 & 2.16 \\
\hline N. Placenta (1NHP) & 734 & 4 & 0.54 \\
\hline N. Melanocyte (2NbHM) & 270 & 7 & 2.53 \\
\hline \multicolumn{4}{|l|}{ N. Multiple Sclerosis Plaques } \\
\hline (2NbHMSP) & 94 & 6 & 6 \\
\hline N. Breast (3NbHBst) & 269 & 0 & 0 \\
\hline N. Adult Brain (N2b5HB55Y) & 189 & 0 & 0 \\
\hline Adult Liver & 647 & 0 & 0 \\
\hline N. Breast (2NbHBst) & 189 & 1 & 0.53 \\
\hline Adult Lung & 263 & 3 & 1.13 \\
\hline N. Adult Brain (N2b4HB55Y) & 91 & 1 & 1.09 \\
\hline N. Placenta (2NbHP8to9W) & 93 & 3 & 3.13 \\
\hline Fetal Spleen & 186 & 5 & 2.62 \\
\hline Placenta & 141 & 1 & 0.7 \\
\hline N. Retina (N2b4HR) & 43 & 1 & 2.27 \\
\hline Fetal Cochlea & 65 & 0 & 0 \\
\hline Ovary & 68 & 0 & 0 \\
\hline N. Fetal Lung (NbHL19W) ${ }^{c}$ & - & - & - \\
\hline N. Retina (N2b5HR) & 25 & 2 & 7.41 \\
\hline Olfactory Epithelium & 51 & 0 & 0 \\
\hline N. Pineal Gland (N3HPG) & 20 & 0 & 0 \\
\hline N. Ovary Tumor (NbHOT) & 25 & 2 & 7.41 \\
\hline Total & 5399 & 57 & 1.04 \\
\hline
\end{tabular}

To examine the representation of different protein families in the EST data we performed a HMM analysis of the translated $5^{\prime}$ EST data as described in Methods. This involves comparison of the query sequence with a "model" constructed from a sequence alignment of multiple members of a protein family. We chose to examine only the 5' ESTs because the HMM analysis is computationally intensive and because 5 ' ESTs are more likely to contain sequence coding for protein. The method is sensitive so that even highly divergent members of well-characterized protein families can be recognized. The method is suited to analysis of ESTs because the sequence of the entire protein need not be known, and the method is somewhat tolerant of frame shifts.

HMM analysis of 139,418 translated 5' ESTs allowed us to assign 10,899 ESTs to all but 39 of a possible 171 protein families for which models could be constructed. Some families had many

Table 6. Discrepancies between ESTs and Human mRNA Sequences

\begin{tabular}{lllll}
\hline High quality & mRNA matches & \% substitutions & \% deletions & \% insertions \\
\hline 5' ESTs $^{\prime}$ 3' ESTs & 3000 & 1.38 & 1.14 & 0.74 \\
& 3000 & 1.6 & 0.94 & 0.42 \\
\hline
\end{tabular}




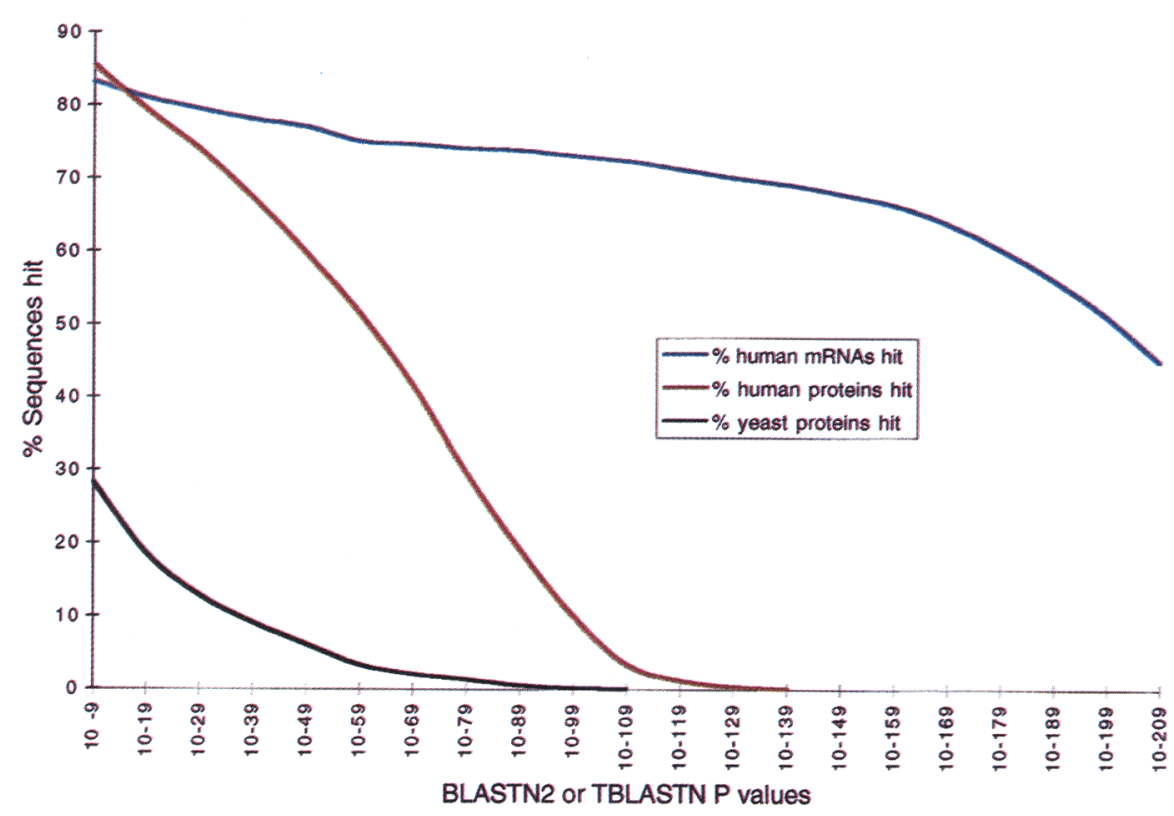

Figure 4 The proportion of sequences from a yeast protein data base, nonredundant human mRNA data base, and human protein data base (all human proteins in SWISS-PROT) showing similarity to at least one human EST. These proportions are shown as a function of $P$ value (smaller $P$ values indicate matches of higher significance), where the $P$ value is calculated by BLASTN2 (nonredundant human mRNA dat abase) or TBLASTN (protein data bases). These data show that a majority of the sequences in the human data bases were represented in our EST data, and that more than $15 \%$ of the yeast proteins were significantly similar to one or more of the human ESTs.

representatives in the EST data. For example, sequences classified as globins by HMM analysis comprised $33 \%(3601 / 10,899)$ of all ESTs that could be assigned to a family. The majority of the globins were contributed by the normalized fetal liver/spleen (1NFLS; 2095 ESTs) and placenta libraries (1NHP; 557 ESTs), and the nonnormalized fetal spleen library (731 ESTs). Although the number of globin sequences contributed by the 1NFLS library was large, globins comprised only $5 \%(2095 / 40,618)$ of all $5^{\prime}$ ESTs from the library. In contrast, globins comprised $24 \%(737 / 3020)$ of all $5^{\prime}$ ESTs obtained from the non-normalized fetal spleen library. This large reduction in the proportion of globin sequences could be due to the effects of normalization, although this cannot be stated with certainty as these two libraries were derived independently from different tissue sources and were not treated identically prior to normalization.

There were other large families that were apparent as a result of the HMM analysis. These included the glyceraldehyde-3-phosphate dehydrogenases (215 ESTs), protein kinases (363
ESTs), ras proteins (363 ESTs), serine protease inhibitors (643 ESTs), actins (191 ESTs), tubulins (310 ESTs), and intermediate filament proteins (173 ESTs). A complete list of the protein families we used for HMM analysis and our results per library are available at http://genome. wustl.edu/est/esthmpg. html/hmm_results.

There were 39 protein families for which representatives could not be identified in the ESTs. To understand why these families were not represented we examined the proteins used in the HMM multiple sequence alignments. For 25 of the 39 nonrepresented families, the HMM alignments were constructed exclusively of bacterial proteins (10/39), mitochondrial proteins (6/ $39)$, plant proteins $(6 / 39)$, viral proteins (2/39), or snake venoms (1/39). Certain alignments contained bacterial, plant, and fungal sequences (8/ 39 ). Given that these 33 alignments contained only prokaryotic or plant proteins, or proteins that we had removed intentionally as contaminants (i.e., mitochondrial proteins) their absence in the EST data is not surprising. Indeed, at least three of these families are specific for photosynthesis (ribulose bisphosphate carboxylase large and small subunits and photosynthetic reaction center proteins).

The six remaining families for which representatives were not found in the EST data include the laminin Bs, the C-type lysozymes, the $\mathrm{Zn}$ proteases, the protein hormones, the interferons, and the peroxidases. There are several possible explanations for the failure of the EST data to contain representatives of these families. These genes may not be expressed in the tissues from which we have obtained cDNA libraries, or they may be expressed at only very low levels in these tissues. Alternatively, there may be a technical reason for their absence. For example, 3' UTRs could be so long that even $5^{\prime}$ ESTs would fall 
HILLIER ET AL.

Table 7. Yeast Proteins Matching Human ESTs

\begin{tabular}{|c|c|c|c|c|}
\hline Reference $^{a}$ & EST & $P$ value & $\begin{array}{l}\text { Accession } \\
\text { no. }\end{array}$ & Description \\
\hline GP-3435 & yu56e04.r1 & $9.00 \mathrm{E}-82$ & V01296 & beta-tubulin \\
\hline GP-3328 & $y w 71 d 04 . r 1$ & $2.20 \mathrm{E}-118$ & V01289 & actin \\
\hline GP-4396 & $y \times 16 a 10 . r 1$ & $1.30 \mathrm{E}-80$ & X17204 & L4 protein \\
\hline SW-H3_YEAST & $y \times 41 c 04.51$ & $4.20 \mathrm{E}-80$ & P02303 & histone h3 \\
\hline GP-472523 & yj93f04.r1 & $2.80 \mathrm{E}-102$ & M27070 & protein phosphatase 1 \\
\hline SW-TBB_YEAST & yu56e04.r1 & $7.10 \mathrm{E}-82$ & P02557 & tubulin beta chain \\
\hline GP-3132̄61 & yv70e08.51 & $1.30 \mathrm{E}-109$ & $X 73532$ & TEF1 gene product \\
\hline GP-914973 & yw82b03.r1 & $6.70 \mathrm{E}-85$ & U32445 & 60 S ribosomal protein L16 \\
\hline GP-172444 & $y \times 16 a 10 . r 1$ & $2.80 E-83$ & M88608 & ribosomal protein $L 4$ \\
\hline GP-172713 & $y \times 25 f 09 . r 1$ & 4.70E-101 & M17583 & 70-kD heat shock protein \\
\hline GP-407521 & $y \times 25 f 09 . r 1$ & $5.50 \mathrm{E}-92$ & Z26879 & chaperone \\
\hline GP-312352 & $y \times 25 f 09 . r 1$ & $6.70 \mathrm{E}-92$ & X12926 & SSA1 protein \\
\hline PIR-HSBY3 & $y \times 41 c 04 . s 1$ & $4.50 \mathrm{E}-81$ & HSBY 3 & histone $\mathrm{H} 3$ \\
\hline GP-671634 & $y \times 60 a 10 . r 1$ & $5.20 \mathrm{E}-83$ & X66206 & pid:q671634 \\
\hline SW-TSA_YEAST & $y \times 71 e 09 . r 1$ & $2.50 \mathrm{E}-80$ & P34760 & thiol-specific antioxidant protein (prp) \\
\hline GP-468426 & $y \times 74 d 12 . r 1$ & $4.90 \mathrm{E}-88$ & L31405 & ribosomal protein S3 \\
\hline SW-RS3_YEAST & $y \times 74 d 12 . r 1$ & $6.10 \mathrm{E}-89$ & P05750 & 40 s ribosomal protein s 3 \\
\hline SW-RS6 YEAST & $y \times 86 d 02 . r 1$ & $7.90 \mathrm{E}-81$ & P02365 & 40 s ribosomal protein $\mathrm{s} 6$ \\
\hline GP-173058 & $y \times 99 h 01 . r 1$ & $1.70 E-87$ & M28429 & alpha tubulin \\
\hline PIR-B22696 & ya02a07.r3 & $2.50 \mathrm{E}-104$ & B22696 & polyubiquitin 6 \\
\hline PIR-D29456 & ya02a07.r3 & 7.70E-92 & D29456 & ubiquitin precursor UB|4 \\
\hline SW-EF1A_YEAST & ya02a12.r3 & $1.50 \mathrm{E}-96$ & P02994 & elongation factor 1 -alpha \\
\hline SW-RHO1_YEAST & yg93g02.r1 & $2.20 \mathrm{E}-80$ & P06780 & rho1 protein \\
\hline SW-PP12_YEAST & yj93f04.r1 & $5.10 \mathrm{E}-103$ & P32598 & serine/threonine protein phosphatase pp $1-2$ \\
\hline SW-DHSĀ_YEAST & yl95a06.r1 & $6.50 \mathrm{E}-81$ & Q00711 & $\begin{array}{l}\text { succinate dehydrogenase (ubiquinone) } \\
\text { flavoprotein subunit precursor }\end{array}$ \\
\hline SW-P2A2_YEAST & $y \mid 95 b 06 . r 1$ & $1.70 \mathrm{E}-97$ & P23595 & $\begin{array}{l}\text { serine-threonine protein phosphatase pp } 2 \mathrm{a}-2 \\
\text { catalytic subunit }\end{array}$ \\
\hline SW-P2A1_YEAST & yl95b06.r1 & $5.60 \mathrm{E}-97$ & P23594 & $\begin{array}{l}\text { serine/threonine protein phosphatase pp2a- } 1 \\
\text { catalytic subunit }\end{array}$ \\
\hline SW-UBC4_YEAST & yp57e01.r1 & $4.90 \mathrm{E}-86$ & P15731 & ubiquitin-conjugating enzyme e2-16 kd \\
\hline SW-UBC5 YEAST & yp57e01.r1 & $6.20 \mathrm{E}-86$ & P15732 & ubiquitin-conjuqating enzyme e2-16 kd \\
\hline SW-GSP2_YEAST & yv41b06.r1 & $1.80 \mathrm{E}-98$ & P32836 & gtp-binding nuclear protein gsp $2 / \mathrm{cnr} 2$ \\
\hline SW-GSP1_YEAST & yv41b06.r1 & $3.20 \mathrm{E}-99$ & P32835 & gtp-binding nuclear protein gsp $1 / \mathrm{cnr} 1$ \\
\hline SW-CC 42 YEAST & yv46d01.r1 & $1.80 \mathrm{E}-85$ & P19073 & cell division control protein 42 \\
\hline PIR-S51452 & yv46d01.r1 & $1.80 \mathrm{E}-85$ & S51452 & cell division control protein CDC 42 \\
\hline SW-TBA3_YEAST & yv70d06.r1 & $8.70 \mathrm{E}-84$ & P09734 & tubulin alpha- 3 chain \\
\hline PIR-S50272 & yw70f12.r1 & $1.50 \mathrm{E}-86$ & S50272 & hypothetical protein YBR1317 \\
\hline SW-RS11_YEAST & $y w 70 f 12 . r 1$ & $3.40 \mathrm{E}-87$ & P05755 & 40s ribosomal protein ys 11 (yp28) (s13) \\
\hline PIR-S1682̄2 & $y w 70 f 12 . r 1$ & $4.70 \mathrm{E}-86$ & S16822 & ribosomal protein S9.e.A \\
\hline SW-ACT_YEAST & $y w 71 \mathrm{~d} 04 . r 1$ & $3.00 \mathrm{E}-118$ & P02579 & actin \\
\hline SW-YPT7̄_YEAST & $y w 76 g 03 . s 1$ & $5.30 \mathrm{E}-84$ & P32939 & qtp-binding protein ypt7 \\
\hline SW-RL16 YEAST & yw82b03.r1 & 4.70E-85 & P06380 & 60 s ribosomal protein 116 \\
\hline PIR-R5BȲ̄ 6 & $y w 82 b 03 . r 1$ & $9.10 \mathrm{E}-86$ & R5BY16 & ribosomal protein L11.e \\
\hline SW-RS41_YEAST & $y w 95 d 08 . s 1$ & $1.60 \mathrm{E}-83$ & P26781 & 40 s ribosomal protein rp41 \\
\hline PIR-S41784 & $y w 95 d 08 . s 1$ & $4.20 \mathrm{E}-82$ & S41784 & ribosomal protein S11.e \\
\hline SW-RL4B_YEAST & $y \times 16 a 10 . r 1$ & $2.40 \mathrm{E}-82$ & P29453 & 60 s ribosomal protein $17 a-1$ \\
\hline PIR-S16810 & $y \times 16 a 10 . r 1$ & $3.10 \mathrm{E}-82$ & S16810 & ribosomal protein L7a.e.B \\
\hline SW-RL4A_YEAST & $y \times 16 a 10 . r 1$ & $3.40 \mathrm{E}-81$ & P17076 & 60 s ribosomal protein $17 a-1$ \\
\hline PIR-R5BY $\overline{7} A$ & $y \times 16 a 10 . r 1$ & 4.40E-81 & R5BY7A & ribosomal protein L7a.e.A \\
\hline PIR-S58785 & $\mathrm{yx} 19 \mathrm{~b} 12 . r 1$ & $2.10 \mathrm{E}-104$ & S58785 & ADP-ribosylation factor 2 \\
\hline PIR-A36367 & $y \times 19 b 12 . r 1$ & $3.00 \mathrm{E}-104$ & A36367 & ADP-ribosylation factor 2 \\
\hline SW-ARF2_YEAST & $y \times 19 b 12 . r 1$ & $5.60 \mathrm{E}-104$ & P19146 & adp-ribosylation factor 2 \\
\hline SW-ARF1 YEAST & $y \times 19 b 12 . r 1$ & $7.80 \mathrm{E}-104$ & P11076 & adp-ribosylation factor 1 \\
\hline
\end{tabular}


Table 7. (Continued)

\begin{tabular}{|c|c|c|c|c|}
\hline Reference $^{a}$ & EST & $P$ value & $\begin{array}{l}\text { Accession } \\
\text { no. }\end{array}$ & Description \\
\hline SW-HS75_YEAST & $y \times 25 f 09 . r 1$ & $1.10 \mathrm{E}-80$ & P11484 & heat shock protein ssb1 \\
\hline PIR-S20149 & $y \times 25 f 09 . r 1$ & $1.30 \mathrm{E}-80$ & S20149 & heat shock cognate protein SSB1 \\
\hline SW-HS76-YEAST & $y \times 25 f 09 . r 1$ & $1.50 \mathrm{E}-80$ & P40150 & heat shock protein ssb2 \\
\hline PIR-S49859 & $y \times 25 f 09 . r 1$ & $1.80 \mathrm{E}-80$ & S49859 & probable heat shock protein N1333 \\
\hline SW-GR78_YEAST & $y \times 25 f 09 . r 1$ & $2.00 \mathrm{E}-80$ & P16474 & $78 \mathrm{kd}$ glucose regulated protein (grp78) \\
\hline SW-HS72_YEAST & $y \times 25 f 09 . r 1$ & $2.00 \mathrm{E}-91$ & P10592 & heat shock protein ssa2 \\
\hline PIR-S20139 & $y \times 25 f 09 . r 1$ & $2.30 \mathrm{E}-91$ & S20139 & heat shock protein SSA2 \\
\hline SW-HS74_YEAST & $y \times 25 f 09 . r 1$ & 4.10E-91 & P22202 & heat shock protein ssa4 \\
\hline PIR-B36590 & $y \times 25 f 09 . r 1$ & 4.70E-91 & B36590 & heat shock protein SSA4 \\
\hline SW-HS71_YEAST & $y \times 25 f 09 . r 1$ & $5.80 \mathrm{E}-92$ & P10591 & heat shock protein ssa1 \\
\hline SW-HS73_YEAST & $y \times 25 f 09 . r 1$ & 7.10E-92 & P09435 & heat shock protein ssa 3 \\
\hline PIR-HHBYA1 & $y \times 25 f 09 . r 1$ & $7.80 \mathrm{E}-92$ & HHBYA1 & heat shock protein SSA1 \\
\hline PIR-S48413 & $y \times 26 a 09 . r 1$ & $3.10 \mathrm{E}-92$ & S48413 & $\begin{array}{l}\text { ribonucleotide reductase large chain } 3 \\
\text { homolog }\end{array}$ \\
\hline SW-RIR1_YEAST & $y \times 26 a 09 . r 1$ & $4.20 \mathrm{E}-86$ & P21524 & $\begin{array}{l}\text { ribonucleoside-diphosphate reductase large } \\
\text { chain } 1\end{array}$ \\
\hline SW-RIR3_YEAST & $\mathrm{y} \times 26 \mathrm{a09} . \mathrm{r} 1$ & $7.80 \mathrm{E}-91$ & P21672 & $\begin{array}{l}\text { ribonucleoside-diphosphate reductase large } \\
\text { chain } 2\end{array}$ \\
\hline PIR-S54490 & $y \times 53 d 11 . r 1$ & $5.10 \mathrm{E}-87$ & S54490 & ribosomal protein $\mathrm{L} 15$ \\
\hline PIR-S48502 & $y \times 53 d 11 . r 1$ & $6.00 \mathrm{E}-87$ & $\$ 48502$ & ribosomal protein L15 \\
\hline SW-RL15_YEAST & $y \times 53 d 11 . r 1$ & $6.60 \mathrm{E}-86$ & P05748 & 60 s ribosomal protein yl10 (113) (rp15r) \\
\hline SW-BMH2_YEAST & $\mathrm{y} \times 60 \mathrm{a} 10 . \mathrm{r} 1$ & $1.00 \mathrm{E}-83$ & P34730 & bmh2 protein \\
\hline PIR-S57278 & $y \times 60 a 10 . r 1$ & $1.40 \mathrm{E}-83$ & S57278 & 14-3-3 protein homolog $\mathrm{Bmh} 2 \mathrm{p}$ \\
\hline PIR-S30863 & $y \times 60 a 10 . r 1$ & $6.90 E-84$ & S30863 & $\mathrm{BMH} 1$ protein \\
\hline PIR-S56166 & $\mathrm{y} \times 60 \mathrm{a} 10 . \mathrm{r} 1$ & $7.20 \mathrm{E}-82$ & S56166 & $\mathrm{BMH} 2$ protein \\
\hline SW-BMH1_YEAST & $y \times 60 a 10 . r 1$ & $9.50 E-84$ & P29311 & bmh1 protein \\
\hline SW-CC28_YEAST & $y \times 64 a 08 . r 1$ & $5.00 \mathrm{E}-82$ & P00546 & cell division control protein 28 \\
\hline SW-RS4E_YEAST & $\mathrm{y} \times 66 \mathrm{c} 10 . \mathrm{r} 1$ & $6.80 \mathrm{E}-93$ & P05753 & 40 s ribosomal protein s4 (s7) (ys6) \\
\hline PIR-S20054 & $\mathrm{y} \times 66 \mathrm{c} 10 . \mathrm{r} 1$ & $9.00 E-93$ & S20054 & ribosomal protein $\$ 4$ \\
\hline PIR-S46695 & $\mathrm{y} \times 66 \mathrm{c} 10 . \mathrm{r} 1$ & $9.80 \mathrm{E}-92$ & S46695 & ribosomal protein $\mathrm{S} 4$ \\
\hline PIR-A47362 & $y \times 71 e 09 . r 1$ & $3.30 \mathrm{E}-80$ & A47362 & thiol-specific antioxidant \\
\hline SW-QSR1_YEAST & $y \times 71$ f07.r1 & $2.40 \mathrm{E}-80$ & P41805 & ubiquinol-cytochrome $\mathrm{c}$ reductase complex \\
\hline PIR-S48510 & $y \times 74 d 12 . r 1$ & $1.10 \mathrm{E}-89$ & $\$ 48510$ & ribosomal protein S3.e \\
\hline PIR-S48401 & $\mathrm{y} \times 76 \mathrm{~b} 11 . \mathrm{r} 1$ & $4.30 \mathrm{E}-80$ & S48401 & ribosomal protein rp22 \\
\hline GP-1151236 & $y \times 86 \mathrm{~d} 02 . r 1$ & $3.50 \mathrm{E}-80$ & U43281 & Lpg18p \\
\hline PIR-S53911 & $y \times 89 c 10 . r 1$ & $1.50 \mathrm{E}-80$ & S53911 & hypothetical protein N2377 \\
\hline SW-FBRL_YEAST & $y \times 93 a 11 . r 1$ & $3.40 \mathrm{E}-80$ & P15646 & fibrillarin (nucleolar protein 1) \\
\hline PIR-A29456 & $y \times 98 c 09 . r 1$ & $1.50 \mathrm{E}-89$ & A29456 & ubiquitin/ribosomal protein CEP 52 \\
\hline SW-TBA1_YEAST & $y \times 99 h 01 . r 1$ & $2.00 \mathrm{E}-87$ & P09733 & tubulin alpha-1 chain \\
\hline PIR-S57550 & yy86e11.r1 & $6.90 \mathrm{E}-80$ & S57550 & hypothetical protein YP9531.10c \\
\hline
\end{tabular}

a Data base from which the yeast sequence was obtained. GP: GenPept; SW: SWISS_PROT; PIR: Protein information resource.

short of sequence that encoded protein, or the 5' ends of the mRNAs may fall short of domains that would identify them as members of these families.

We tested the possibility that the normalization procedure was eliminating members of gene families, focusing our attention on ESTs identified as tubulins. We first recovered the $3^{\prime}$ ESTs corresponding to those cDNAs of which the $5^{\prime}$ ESTs had been identified as tubulins by HMM analysis and compared these with each other using the DNA sequence assembly engine PHRAP 


\section{HILLIER ET AL.}

using stringent parameters (P. Green, unpubl.). Only those ESTs derived from the same gene and containing overlapping sequences would be assembled into a single cluster.

This analysis was performed for the normalized fetal spleen (1NFLS) and normalized infant brain (1NIB) libraries. The 1NFLS library yielded $803^{\prime}$ ESTs whose corresponding 5' ESTs had been identified as tubulins. PHRAP assembly of these resulted in 9 clusters, each containing at least 2 ESTs. The largest cluster contained 31 ESTs. Six ESTs could not be assembled into clusters because of insufficient similarity to other tubulin sequences and were therefore considered singletons. This yielded 15 different tubulin EST types, six of which contained only single ESTs. Analysis of ESTs from the 1NIB library yielded a similar result; there we found 11 clusters and 12 singlets for a total of 23 tubulin EST types. Taken together, these observations provide strong support for the contention that normalization does not result in the complete removal of gene family members from cDNA libraries.

\section{DISCUSSION}

A key resource for any EST project is the cDNA libraries from which sequence reads are to be derived. Early in the project, only commercially prepared non-normalized libraries were available. We commenced full-scale production sequencing when normalized libraries became available to us in mid-January of 1995 through the IMAGE consortium (Lennon et al. 1996). Since then, these libraries have been the focus of our efforts. In a project whose primary aim is the identification of as many different genes as possible, normalized cDNA libraries have the distinct advantage of having a more uniform representation than nonnormalized libraries, where cDNAs are present in proportion to their expression level. Normalized libraries use a hybridization step to reduce relative representation of abundantly expressed genes (Soares et al. 1994; Bonaldo et al., this issue), thereby increasing the proportion of different genes sampled.

In monitoring bacterial sequences and nonrecombinant plasmids, we found that most normalized libraries (Bonaldo et al., this issue) contained relatively few bacterial sequences and virtually no nonrecombinant clones. By clustering the 3 ' ESTs, which should provide a gene-specific anchored tag for each cDNA, we monitored the level of redundant representation. Because many
cDNAs are not full-length, the 5' ESTs are not similarly anchored and cannot provide a reliable estimate of redundancy or gene representation. For different libraries an unacceptable level of redundancy was attained after different numbers of sequences. For example, the 1NFLS library remains, even after extensive sampling, a relatively rich source of new information. Our analysis of various potential artifacts has shown that this complexity is not a result of problems in library construction, but is likely a reflection of the tissue from which the library was prepared. In contrast, the normalized adult brain libraries were largely redundant after minimal sampling. The process of normalization itself is apparently insufficient to guarantee library complexity, which must also depend on the tissue source.

Comparison of the 3' ESTs from all 22 libraries and grouping of identical sequences allowed us to estimate the number of unique cDNAs in the data set to be 44,377 , a rough estimate of the number of genes sampled. With the problems created by the limited accuracy of singlesequence reads, alternative splicing, alternative polyadenylation sites, and similarity between gene family members, a more accurate estimation awaits interactive analysis of the data and directed collection of additional sequences. Comparison of the results of this cluster analysis with earlier studies (Adams et al. 1995) is also problematic, because most of the sequences generated in that study were derived from unanchored 5' ends or from unoriented libraries and are not publicly available.

Comparisons of the EST data to other publicly available data show that the ESTs provide an estimate of the fraction of all human genes represented. In the case of the human mRNA data base, ESTs represented over $70 \%$ of the 4169 sequences at $P$ values of $10^{-109}$ or better. An ongoing comparison conducted at the National Center for Biotechnology Information (NCBI; Bassett et al. 1996) shows that, as of April 1996, our data included tags for $33 / 60(55 \%)$ of the positionally cloned human disease loci (see http://www.ncbi. nlm.nih.gov/dbEST/dbEST_genes). HMM analysis has shown that the EST data contains representatives of $77 \%$ of the protein families for which multiple sequence alignments have been constructed (Sonnhammer et al. 1996). When those protein families containing only bacterial, plant, fungus, or viral sequences (or combinations thereof) are removed from consideration, this percentage increases to $96 \%$. Although these 
numbers could be interpreted collectively to mean that we have identified in excess of $50 \%$ of human genes this must be an overestimate, because all of these data are biased toward genes expressed abundantly.

The identification of over 44,000 different EST clusters from 111,000 different clones is fewer than predicted by Poisson statistics for a population with uniform representation of transcripts arising from approximately 100,000 different genes. Of course, the mRNA population from which these cDNAs are derived is not uniform. The diversity we observe in our data set is presumably enhanced by the use of normalized libraries. In order to increase the number of genes represented by our set, we will sample from additional tissues. Still, rare transcripts (e.g., those present as only a single copy in a cell with hundreds of thousands of mRNA molecules) will be difficult to obtain, and common genes will be sampled repeatedly even in new tissues. Subtraction methods now under development (Bonaldo et al., this issue) may help to increase the representation of rare transcripts and extend the utility of current libraries.

The EST data presented here have proven useful for gene-based mapping strategies (Hawthorn and Cowell 1996; McGuire et al. 1996), with more than 13,600 already placed on the human physical map (M. Boguski, unpubl.). The redundancy of data for the more abundant cDNAs from multiple sources has proven useful for the identification of single-base polymorphisms (P. Kwok, pers. comm.). For genomic sequence annotation purposes, however, it is desirable to obtain the complete, accurate sequence from a nonredundant set of cDNA clones. We are developing such a set based on cluster analysis. In the meantime, ESTs are proving useful in sequence annotation. Groups currently annotate human genomic sequence by relying primarily on the similarities to protein and EST data bases and only secondarily on gene prediction programs, especially for information about the splicing and joining of exons to form genes (G. Miklem and A. King, unpubl.). Similarly, information about UTRs and starting/ending positions of messages depends largely on the additional information provided by the EST data. The data also has been used by individual investigators looking for a human representative of their gene of interest. In fact, half of all clones requested in the early phases of the project represented new human homologs of genes known previously only in other species (G. Lennon, unpubl.). Each cDNA clone is available and can be used to expedite isolation and sequencing of the gene of interest and as a probe to examine tissue-specific or developmentally regulated expression or the cloning of related genes from different species. This growing set of human ESTs, available in the public data bases, should immediately and positively affect the rate of disease gene discovery and the advancement of human biology.

\section{METHODS}

\section{Sources of Material}

Although we have sequenced primarily from normalized libraries, we have generated a relatively small number of sequences from non-normalized libraries. These included the following commercial libraries: Stratagene (La Jolla, CA) lung (\#937210), Stratagene placenta (\#937225), Stratagene fetal spleen (\#937205), Stratagene liver (\#937224), and Stratagene ovary (\#937217). Other nonnormalized libraries were kindly donated by N. Robertson and C. Morton (Harvard Medical School; Brigham and Women's Hospital; Boston, MA) (fetal cochlea; Robertson et al. 1994) and N. Walker and D. Lancet (an olfactory epithelium library constructed at the Weizmann Institute of Science). All normalized libraries were constructed in the lab of B. Soares (Bonaldo et al., this issue) and were provided by the IMAGE Consortium (Lennon et al. 1996).

\section{Preparation of DNA}

Frozen glycerol stocks of cDNA clones to be end-sequenced were received in 384-well format and thawed at room temperature. $5 \mu \mathrm{l}$ of each glycerol stock were added, using a 12-channel pipettor, to $1 \mathrm{ml}$ of terrific broth (DIFCO) containing the appropriate antibiotic in a 96 -well block. Bacterial cell cultures were incubated at $37^{\circ} \mathrm{C}$ for $24 \mathrm{hr}$ with shaking at $310 \mathrm{rpm}$ in a incubator shaker (Labline) and then processed. For the majority of the ESTs, high-quality DNA was prepared using the 96-Well Miniprep Kit obtained from Advanced Genetic Technologies Corp. (AGTC, Rockville, MD) following the manufacturer's recommendations, except that bacterial pellets were initially resuspended in $50 \mathrm{ml}$ of sterile distilled water. This AGTC kit uses a boiling step in the DNA isolation process. More recently, high-quality DNA has been prepared using the AGTC 96-Well Alkaline Lysis Miniprep Kit. We find that DNA yield and sample throughput are somewhat improved at no detectable loss in DNA quality as measured by sequencing success. DNA preparations were simultaneously performed on four 96-well culture-containing blocks, providing sufficiently high throughput. The final DNA pellet was resuspended in $70 \mu \mathrm{l}$ or $140 \mu \mathrm{l}$ of $10 \mathrm{~mm}$ Tris pH 8.0, 0.1 mM EDTA. Final DNA concentrations were $-100-400 \mathrm{ng} / \mu \mathrm{l}$. The success of the procedure was verified by electrophoresis, on $0.7 \%$ agarose, of 96 randomly selected DNAs from each set of four 96-well blocks. This 


\section{HILLIER ET AL.}

material was sequenced directly without additional quantitation.

\section{Restriction Enzyme Digestion of cDNA Clones}

For libraries constructed in pT7T3Pac and the normalized infant brain library constructed in the Lafmid BA vector, 1 $\mu \mathrm{l}$ of DNA (50-200 ng) was incubated with $7.75 \mu$ l sterile ddH20, $1 \mu$ l of $10 \times$ SuRE/Cut Buffer " $B$ " (Boehringer Mannheim), and $0.125 \mu \mathrm{l}$ (5 units) each of HindIII and EcoRI. Recognition sites for these enzymes occur close to the cDNA insert in the polylinker of the vector. Double digestion with these enzymes releases the cDNA insert from the vector. Typically, "master mixes" containing all of the reaction components except the DNA were assembled on ice, and $9 \mu$ l of the master mix were aliquoted into 96-well Cycleplates (Robbins Scientific, Sunnyvale, CA) using a Robbins Scientific Hydra 96-channel mechanical pipetting device (Robbins Scientific). DNA samples were then added to wells containing the master mix. Cycleplates were subjected to a brief centrifugation in a model GR- 422 refrigerated floor centrifuge (Jouan) fitted with microtiter plate carriers. Cycleplates were sealed with Scotch Brand heavy duty aluminum foil tape and floated in a $37^{\circ} \mathrm{C}$ waterbath for a minimum of $1 \mathrm{hr}$. cDNAs contained in pBluescript (Stratagene) were treated similarly except that HindIII was replaced with $X$ hoI. After incubation, samples were centrifuged briefly to collect the reactions in the bottoms of the wells and $2 \mu$ l of $6 \times$ loading dye II (Sambrook et al. 1989) were added. Samples were stored at $4^{\circ} \mathrm{C}$ prior to electrophoresis.

\section{Agarose Gel Electrophoresis and cDNA Size Determination}

$1.8 \%$ agarose gels (SeaKem LE, FMC Bioproducts, Rockland $\mathrm{ME}$ ) in $1 \times$ TAE (Sambrook et al. 1989) containing $48 \mu \mathrm{g} / 1$ ethidium bromide were cast in gel trays constructed of UV transparent plastic following a design of $\mathrm{B}$. Brownstein (unpubl.) modified by D. Panussis (unpubl.). Gel dimensions were $22.4 \mathrm{~cm}$ long $\times 13.2 \mathrm{~cm}$ wide. Slots for 4 combs were machined into the gel casting tray at $5.2-\mathrm{cm}$ intervals. Combs were designed to form 24 sample wells with two flanking wells for size standard markers. Sample wellto-well spacing was $0.475 \mathrm{~cm}$ (measured center to center), which permitted the use of 12-channel pipettors in sample loading. Each gel could thus accommodate 96 samples divided among four separate rows, with each row containing two marker lanes. Electrophoresis was conducted in $1 \times$ TAE in a buffer tank constructed to stack two gel trays at once. In this way high-throughput electrophoresis was achieved, with each electrophoresis apparatus separating $2 \times 96$ samples per run. Gels were run at $2.1 \mathrm{~V} / \mathrm{cm}$ (distance measured between the electrodes) for approximately $3 \mathrm{hr}$, or until the bromophenol blue marker band had nearly reached the next set of wells in the gel. Gels were imaged using a Fluorimager SI Vistra (Molecular Dynamics) with scanner control settings as follows: pixel size, 200 $\mu \mathrm{m}$; digital resolution, 16 bits; detection sensitivity, normal; PMT voltage, 750. Restriction fragment sizes were obtained semi-interactively using FragmeNT Analysis version 1.1 (Molecular Dynamics) and comparison to DNA size standard VI (Boehringer Mannheim) for all samples that showed complete digestion and were free of apparent contaminating restriction fragments.

An alternative method used to determine the sizes of a small number of cDNA inserts early in the project was the polymerase chain reaction (PCR; Saiki et al. 1988) using vector specific primers flanking the cDNA insert. Electrophoresis and sample analysis were as described above.

\section{DNA Sequencing}

Di-deoxy terminator sequencing reactions (Sanger et al. 1977) were performed as described (Fulton and Wilson 1994) or with the following modifications. In the second half of the project we made extensive use of ThermoSequenase DNA polymerase and DYEnamic ET dye primers (Amersham). Sequencing reactions contained 1.5 units of ThermoSequenase and were assembled essentially as described by the manufacturer (Amersham). Dye primer cycle sequencing reactions were conducted in a 96-well format using a MJ Research PTC 200 thermal cycler. Temperature profiles were as follows. For M13 Universal and T3 dye-primer sequencing reactions, the profile was: $95^{\circ} \mathrm{C}, 4$ $\mathrm{sec} ; 55^{\circ} \mathrm{C}, 10 \mathrm{sec} ; 70^{\circ} \mathrm{C}, 60 \mathrm{sec}$; for a total of 15 cycles, followed by 15 cycles of: $95^{\circ} \mathrm{C}, 4 \mathrm{sec} ; 70^{\circ} \mathrm{C}, 60 \mathrm{sec}$. For $\mathrm{M} 13$ Reverse dye-primer sequencing reactions, the profile was the same except the annealing temperature was $50^{\circ} \mathrm{C}$. The dye primers used on each of the libraries and the primer sequences are given in Table 8 . After thermal cycling, sequencing reactions were ethanol precipitated, resuspended in loading buffer containing formamide, denatured, and electrophoresed on $\mathrm{ABI} 373$ or 377 sequencing machines.

\section{Initial Data Processing and Submission of Data to dbEST}

Following gel image analysis and DNA sequence extraction, $\mathrm{ABI}$ sequence data were automatically processed to: (1) assess EST quality; (2) trim flanking vector sequences; (3) mask repetitive elements; (4) remove contaminated ESTs; (5) identify similarities to ribosomal RNA, human mRNA, and a nonredundant protein data base; (6) identify other cloning artifacts; and (7) determine which portion of the EST to submit. The resulting sequences were annotated with similarity information, sequence quality information (i.e., position in the sequence at which highquality data ends), and other pertinent information (e.g., library information) and submitted to dbEST/GenBank typically within $48 \mathrm{hr}$ after reaction products had completed gel electrophesis. The details of these procedures follow.

\section{EST Quality}

An assessment of EST quality was achieved using peak to highest noncalled peak signal-to-noise ratios and peak to shoulder-width ratios to determine the base position of the start and stop of the high-quality portion of the EST. 
Table 8. Sequencing Primers

\begin{tabular}{|c|c|c|c|c|c|c|c|c|}
\hline Vector & Libraries $^{a}$ & $\begin{array}{l}\text { Vector } \\
\text { source }\end{array}$ & $\begin{array}{l}\text { Primers } \\
\text { tested }^{\mathrm{b}}\end{array}$ & $\begin{array}{l}\text { bp } \\
\text { from } \\
\text { CDNAc }\end{array}$ & $\begin{array}{l}\text { Signal } \\
\text { inten- } \\
\text { sity }\end{array}$ & $\begin{array}{l}\text { Preferred } \\
\text { primers }\end{array}$ & $\begin{array}{l}\text { Primer } \\
\text { source }\end{array}$ & $\begin{array}{l}\text { Primer sequences } \\
5^{\prime}-3^{\prime}\end{array}$ \\
\hline \multirow[t]{4}{*}{$\begin{array}{l}\text { pBlue- } \\
\text { script }\end{array}$} & Stratagene (5) & \multirow[t]{4}{*}{$\begin{array}{l}\text { Strata- } \\
\text { gene }\end{array}$} & $\begin{array}{l}\text { M13RP } \\
\left(5^{\prime}\right)\end{array}$ & 102 & $\star \star$ & & $A B I$ & $\begin{array}{l}\text { CAGGAAACAGCT- } \\
\text { ATGACC }\end{array}$ \\
\hline & $\begin{array}{l}\text { Olfactory } \\
\text { epithelium } \\
\text { library }\end{array}$ & & T3 $\left(5^{\prime}\right)$ & 67 & * & $T 3\left(5^{\prime}\right)$ & $A B I$ & $\begin{array}{l}\text { ATTAACCCTCAC- } \\
\text { TAAAGGGA }\end{array}$ \\
\hline & \multirow{2}{*}{$\begin{array}{l}\text { Fetal } \\
\text { cochlea } \\
\text { library }\end{array}$} & & $\begin{array}{l}\text { M13UP } \\
\left(3^{\prime}\right)\end{array}$ & 53 & $\star *$ & \multirow[t]{2}{*}{$\begin{array}{l}\text { M13UP } \\
\left(3^{\prime}\right)\end{array}$} & $A B I$ & $\begin{array}{l}\text { TGTAAAACGACG- } \\
\text { GCCAGT }\end{array}$ \\
\hline & & & T7 (3') & 26 & * & & $A B I$ & $\begin{array}{l}\text { TAATACGACTCA- } \\
\text { CTATAGGG }\end{array}$ \\
\hline \multirow[t]{3}{*}{$\begin{array}{l}\text { Lafmid } \\
\text { BA }\end{array}$} & \multirow[t]{3}{*}{$\begin{array}{l}\text { Soares } \\
\text { 1NIB }\end{array}$} & \multirow[t]{3}{*}{ Soares } & $\begin{array}{l}\text { M13RP } \\
\left(5^{\prime}\right)\end{array}$ & 12 & $\star \star$ & \multirow[t]{2}{*}{$\begin{array}{l}\text { M13RP } \\
\left(5^{\prime}\right)\end{array}$} & $A B I$ & $\begin{array}{l}\text { CAGGAAACAGCT } \\
\text { ATGACC }\end{array}$ \\
\hline & & & & 17 & - & & $A B I$ & $\begin{array}{l}\text { TGTAAAACGACG- } \\
\text { GCCAGT }\end{array}$ \\
\hline & & & $\begin{array}{l}\text { M13-40 } \\
\quad \text { UP (3') }\end{array}$ & 37 & $\star \star$ & $\begin{array}{l}\text { M13-40 } \\
\text { UP (3') }\end{array}$ & Promega & $\begin{array}{l}\text { GTITCCCAGTC- } \\
\text { ACGAC }\end{array}$ \\
\hline \multirow[t]{7}{*}{$\begin{array}{l}\text { pT7T3- } \\
\text { Pac }\end{array}$} & \multirow[t]{7}{*}{$\begin{array}{r}\text { Soares } \\
(14)\end{array}$} & \multirow[t]{7}{*}{$\begin{array}{l}\text { Pharm- } \\
\text { acia }\end{array}$} & $\begin{array}{l}\text { M13RP } \\
\left(5^{\prime}\right)\end{array}$ & 46 & - & & $A B I$ & $\begin{array}{l}\text { CAGGAAACAGCT. } \\
\text { ATGACC }\end{array}$ \\
\hline & & & $\begin{array}{l}\text { M13RP } \\
\text { Mod. } \\
\left(5^{\prime}\right)\end{array}$ & 46 & $* *$ & & Promega & $\begin{array}{l}\text { CAGGAAACACCT } \\
\text { ATGAC }\end{array}$ \\
\hline & & & $\begin{array}{l}\text { M13REV2 } \\
\text { ET (5') }\end{array}$ & 43 & 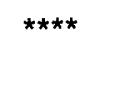 & \multirow[t]{2}{*}{$\begin{array}{l}\text { M13REV2 } \\
\text { ET (5') }\end{array}$} & $\begin{array}{l}\text { Amer- } \\
\text { sham }\end{array}$ & $\begin{array}{l}\text { AGGAAACAGCTA- } \\
\text { TGACATG }\end{array}$ \\
\hline & & & $\begin{array}{l}\text { M13UP } \\
\left(3^{\prime}\right)\end{array}$ & 38 & $* *$ & & $\begin{array}{c}\mathrm{ABI} / \text { Pro- } \\
\text { mega }\end{array}$ & $\begin{array}{l}\text { TGTAAAACGACG- } \\
\text { GCCAGT }\end{array}$ \\
\hline & & & $\begin{array}{l}\text { M13-40UP } \\
\text { ET (3') }\end{array}$ & 38 & $\star \star \star \star *$ & \multirow[t]{3}{*}{$\begin{array}{l}\text { M13UP- } \\
40 \mathrm{ET} \\
\left(3^{\prime}\right)\end{array}$} & $\begin{array}{l}\text { Amer- } \\
\text { sham }\end{array}$ & $\begin{array}{l}\text { GTITCCCAGTC- } \\
\text { ACGACG }\end{array}$ \\
\hline & & & $\mathrm{T7}\left(5^{\prime}\right)$ & 12 & * & & $A B I$ & $\begin{array}{l}\text { TAATACGACTCA- } \\
\text { CTATAGGG }\end{array}$ \\
\hline & & & T3 $\left(3^{\prime}\right)$ & 7 & * & & $A B I$ & $\begin{array}{l}\text { ATTAACCCTCAC- } \\
\text { TAAAGGGA }\end{array}$ \\
\hline
\end{tabular}

ESTs with $25 \%$ or more ambiguous base calls ("Ns") were removed as were ESTs with 50 or fewer bases of high or intermediate quality sequence. We elected to submit shorter high-quality sequences not less than 50 bases for two reasons. First, this length is sufficient to provide an unambiguous gene tag and permit development of STSs. Second, sequences this length were relatively rare. Sequences shorter than 50 bases were submitted only if they showed similarity to a data-base entry. We also elected to submit some lower quality data extending beyond regions of high quality (see below) because this too can be of use. Individual evaluation of the quality of each EST is made possible by the availability of all trace data over the internet from our server.

\section{Removal of Vector Sequences and Masking of Repeats}

Vector sequences were trimmed using the programs VEP (Dear and Staden 1991), WEP (W. Gish, unpubl.) and BLASTN ( $\mathrm{S}=133, \mathrm{~S} 2=133, \mathrm{M}=5, \mathrm{~N}=-8)$. WEP also served to identify incorrect adaptor sequences and 3 ' ESTs lacking poly(A) tails. Repetitive elements were then iden- 


\section{HILLIER ET AL.}

tified and masked as follows. HMMFS (S. Eddy and G. Miklem, unpubl.) and REP (Dear and Staden 1991) were used to mask Alu sequences. blastx_and_mask (G. Miklem, unpubl.), which uses BLASTX ( $S=50$ ) against a data base of human repetitive elements translated in all six frames, was used to mask other human repetitive elements. The programs TANDEM and INVERTED (R. Durbin, unpubl.) were used to mask local tandem and inverted repeats, and BLASTN ( $S=100$ ) of ESTs against a data base of homopolymeric runs was used to identify and mask homopolymer runs.

\section{Contaminating Sequences}

Sequences determined to be vector (BLASTN $S=133$, $\mathrm{S} 2=133, \mathrm{M}=5, \mathrm{~N}=-11, \mathrm{~W}=8$ against a vector subset of GenBank), bacterial (BLASTN $S=133, S 2=133, M=5$, $\mathrm{N}=-11$ against the bacterial division of GenBank) or mitochondrial (BLASTN S $=133, S 2=133, \mathrm{M}=5, \mathrm{~N}=-11$ against Genbank: HUMMTCG, the human mitochondrion complete genome sequence) were not submitted to the public data bases or included in further analysis. Thresholds for EST matches to "contaminating" sequence is a critical issue. For any threshold, one or more examples of possible contaminants could be found in the large data sets we process. In general, we have tried to set the threshold criteria to avoid identifying a human sequence with a similarity to a bacterial gene as bacterial and thereby withhold a useful sequence. This policy undoubtedly results in the rare submission of bacterial sequences.

\section{Identification of Similarities to Existing Data Sets}

EST similarities to ribosomal RNA were identified using BLASTN ( $\mathrm{S}=133, \mathrm{~S} 2=133, \mathrm{M}=5, \mathrm{~N}=-11$ ) to compare the entire masked EST extending through the lower quality data with the RNA division of GenBank. EST similarities to human mRNAs were identified using BLASTN $(S=133$, $\mathrm{S} 2=133, \mathrm{M}=5, \mathrm{~N}=-11$ ) in searches against a nonredundant human mRNA data base. Similarities to proteins were identified using BLASTX $(S=100)$ searches against SWIR, which is a nonredundant protein data base containing sequences culled from PIR, SWISS-PROT, and a data base of predicted C. elegans proteins called WORMPEP (E. Sonnhammer, unpubl.).

\section{EST Data-base Submission}

Generally ESTs are submitted from the first high-quality base to the position where two ambiguous base calls (Ns) in five bases are found after the last high-quality base. For high-quality ESTs exhibiting strong BLAST scores this rule was followed if the similarity segment ended before the end of the high-quality region; alternatively, if the BLAST alignment extended beyond the high-quality region, the sequences up until the end of the alignment were submitted. ESTs with no high-quality sequence were nonetheless processed through all the above searches; those that had significant similarity to the GenBank RNA subsection, nonredundant protein data base, or nonredundant human
mRNA data base were submitted with the expectation that such sequences and their traces could be of use. In these cases only the portion of the EST that is identified in the BLAST alignment is submitted (in rare cases this has resulted in a submission of fewer than 50 bases).

\section{Comparisons with Other Publicly Available Data}

To perform comparative analyses, we considered all our submitted data as of April 1, 1996 (280,223 ESTs). These were masked for known human repetitive elements and low entropy sequences as described above to provide a data base against which to conduct the following searches. Each human protein in SWISS-PROT release 32 (3281 proteins) was compared with our ESTs using TBLASTN (version 1.4) with the parameters $M=$ BLOSUM62, $S=100$. The program MSPcrunch (Sonnhammer and Durbin 1994) was used to remove low-entropy similarities. Using the BLOSUM62 amino acid scoring matrix as opposed to the PAM120 or PAM180 scoring matrices biased the results against short stretches of identity. The proportion of human proteins in this data base hit by at least one EST was then determined for $15 P$ values between $10^{-9}$ and $10^{-149}$ in $10^{-10}$ increments.

\section{Comparisons with the Human mRNA Data Base}

A nonredundant human mRNA data base (Boguski and Schuler 1995) of 4169 human sequences was compiled from GenBank release 94 . These sequences were compared with our data set using BLASTN2 (W. Gish, in prep.) with the following parameters: $\mathrm{S}$ (score corresponding to minimum significance for a single alignment $)=170$, gapS2 $($ minimum reported score $)=150, \mathrm{M}($ match $)=5, \mathrm{~N}$ (mismatch $)=-11, \mathrm{Q}($ gap initiation penalty $)=11, \mathrm{R}($ gap extension penalty) $=11, \mathrm{~B}=5000$, filter $=$ seg (removes lowentropy sequences such as homopolymeric tracts from consideration). Unlike BLAST (Altschul et al. 1990), BLASTN2 permits gaps, thereby allowing alignments that included insertions and deletions to be included in the comparison. The proportion of sequences in this data base hit by at least one EST was then determined for $15 P$ values between $10^{-9}$ and $10^{-209}$ in $10^{-10}$ increments.

\section{Measuring the Frequency of Discrepancies}

We obtained an estimate for the average frequency of discrepancies between ESTs and sequences in the nonredundant human mRNA data base as follows. BLAST searches were performed to identify 3000 mRNAs that had hits to both 5' and 3' ESTs generated from the same cDNA clone. The 5' and 3' EST alignments to the human mRNA sequence were then examined in detail using cross_match (P. Green, unpubl.), a modified Smith-Waterman alignment program. The discrepancies thus identified were classified as substitutions (which included ambiguous bases, or Ns), deletions (bases not present in the EST sequence but present in the mRNA sequence), or insertions (bases present in the EST but not present in the mRNA sequence). For each of these categories the total number of discrep- 


\section{GENERATION AND ANALYSIS OF 280,000 HUMAN ESTs}

ancies per number of bases in the alignment was computed and then averaged across all 5' EST alignments and across all 3' EST alignments. Two such calculations were performed, one for the regions of sequences annotated as high-quality in the dbEST entry, and one for the entire length of the submitted EST, which included regions considered to be of lower quality. Rates of substitution, deletion, and insertion errors as they are distributed along the length of the sequence were also calculated for the highquality portions of the $60005^{\prime}$ and $3^{\prime}$ EST sequences.

\section{3' Clustering to Assay Library Complexity}

We applied a clustering algorithm that demanded that $3^{\prime}$ ESTs derived from the same poly(A) tract should align at the ends, thus providing an estimate of the number of anchored 3' ESTs. The 136,474 3' ESTs obtained from all libraries were processed as follows: All ESTs containing known repeats were removed and any $5^{\prime}$ polyT regions were trimmed. Any EST containing more than 30 bases of low-entropy sequence [as defined by "dust" (R. Tatusov and D. Lipman, in prep.)] was removed. All ESTs were trimmed back to their high-quality stop position as indicated in each dbEST entry. Any EST less than 150 bases was removed from consideration. This left 111,189 high quality 3' ESTs for the remaining analyses. Bases 40-140 of each EST $[40$ bases upstream of the poly(T) tract (approximately bases $90-190$, the highest quality portion of the original trace)] were then used in comparisons with the full length of all other ESTs in the set using BLASTN2 and the following parameters: $S=170$, gapS2 $=150, M=5$, $\mathrm{N}=-11, \mathrm{Q}=11, \mathrm{R}=11$. Each EST that showed greater than $95 \%$ identity on the correct strand, covered at least bases $50-130$ of the 101 base query sequence, and the similarity of which ended before base 200 of the subject sequence was considered for pairwise comparisons. Pairwise comparisons of the full length of these $3^{\prime}$ ESTs were performed using cross_match (P. Green, unpubl.) with the following parameters: -minmatch 12 , -minscore 80 , -penalty -2,-gap_init -4, -gap_ext -4 .

After the full-length Smith-Waterman pairwise comparisons, ESTs showing less than $8 \%$ mismatch across the full length of the EST were considered identical. The criterion of $8 \%$ mismatch was chosen empirically to reflect the increased error associated with the full length of the ESTs included in the alignments and because the first step in the analysis (the $3^{\prime}$ EST anchoring by the initial BLAST comparisons) was considered sufficiently stringent to exclude matches between related but nonidentical ESTs. ESTs were then grouped into clusters based on their pairwise similarities. The ESTs that could not be grouped into clusters were used to calculate the proportion of singletons contributed by each library to the entire data set. To examine the depletion of the singletons within each library, only intralibrary similarities were considered. The number of singletons as a fraction of the number of ESTs sampled in that library was calculated at intervals of 500 sequences as described above.

\section{Internal Priming}

To obtain an estimate of the frequency of internal priming per library, the results of the comparison between our masked EST data set and the nonredundant human mRNA data base were used. All ESTs showing similarity to an mRNA sequence with a $P$ value of $10^{-100}$ or better were examined. The 3' ESTs showing similarities at these levels on the "correct strand" were classified as follows: (1) 3' EST whose similarity fell within 50 bases of the end of the human mRNA sequence; (2) 3' EST whose similarity ended before 50 bases from the end of the human mRNA, but another EST showed similarity in that region; and (3) 3' EST whose similarity fell more than 50 bases from the end of the human mRNA, and no other EST showed similarity in that region. Only those meeting the latter criterion were judged to be a candidate nonspecifically primed cDNAs.

\section{Estimating the Frequency of Chimeric Clones and the Frequency of Inverted Clones}

From the results of the comparison between our masked EST data set and the nonredundant human mRNA data base, an estimate of the frequency of chimeric clones was obtained. All 3' ESTs showing similarity to a human mRNA sequence at a probability of $10^{-100}$ or better were considered for this analysis. If the $3^{\prime}$ EST matched and the corresponding 5' EST had not been successful (failed during initial sequencing), the match was not considered. If both the 5' and 3' ESTs matched the same human mRNA sequence at the $10^{-100}$ cutoff the cDNA clone was considered unlikely to be a chimera. Conversely, if the $3^{\prime}$ EST matched a human mRNA and the 5' EST was submitted to dbEST but failed to match the same human mRNA, the cDNA from which the ESTs were derived was considered potentially chimeric. In a similar fashion, using the results of the comparison between our masked EST data set and the nonredundant human mRNA data base, we generated an estimate of the frequency of reversed (or flipped) clones. The BLASTN2 alignments of all 3' ESTs matching a human mRNA sequence with a $P$ value of $10^{-100}$ or better were examined. Matches categorized as being on the minus strand were considered to identify cDNAs in the correct orientation; conversely, matches on the plus (or coding) strand were considered to identify cDNAs that were in inverted orientation.

\section{Comparisons with Human Genomic Sequence}

The 176 human genomic sequences larger than $25 \mathrm{~kb}$ as of April 7, 1996 (a total of 8,244,729 bases) were retrieved from GenBank release 94 . These were compared with our masked ESTs using BLASTN2 and the following parameters: $S=170$, gapS2 $=150, M=5, N=-11, Q=11$, $\mathrm{R}=11$. All ESTs showing similarity to the genomic sequence with a $P$ value of $10^{-100}$ or better were categorized as described in Results.

\section{Comparisons with Protein Families}

The 171 available seed alignments for protein families were obtained (Eddy 1995; Sonnhammer et al. 1996) and HMMs were built using the hmmer-1.9j package with the 


\section{HILLIER ET AL.}

following building parameters: hmmb -d -R -PBLOSUM62. The $-d$ option allows for maximum discrimination; the $-R$ option allows that some family members may be fragmentary (useful for EST data); and BLOSUM62 (Henikoff and Henikoff 1992) is the scoring matrix used. The program HMMFS was then used to search the resulting HMMs against the entire set of $5^{\prime}$ ESTs, translated in all six frames using the program "orfer" (S. Eddy, unpubl.). A cutoff score of 20.0 bits was used to determine whether a given clone belonged to a given family. This is a log-odds score; a score of 20 indicates that a sequence is $2^{20}$-fold more likely to match the HMM than not. The use of HMMs in general and the hmmer-1.9j package specifically is detailed in a users' guide available upon request from Sean Eddy (eddy@genetics.wustl.edu).

\section{Comparison of ESTs with a Yeast Protein Data Base}

A nonredundant yeast protein data base (yeast_nrpep. fasta) containing 8269 yeast proteins was obtained from www-genome.stanford.edu on June 11, 1996. This data base contains yeast proteins culled from SWISS-PROT, GenPept, and PIR, with redundant entries (only 100\% identical amino acid sequences) removed. Each of the yeast proteins was compared with the entire set of masked $5^{\prime}$ and $3^{\prime}$ ESTs using TBLASTN and the following parameters: $M=$ PAM120, $T=17, W=4, V=10000$, filter $=$ seg. The number of yeast proteins with similarities to ESTs was then calculated for decreasing $P$ values commencing at $10^{-9}$.

\section{ACKNOWLEDGMENTS}

The authors wish to thank Drs. A. Williamson, K. Elliston, and J. Aaronson for support in all aspects of the project, Drs. D. Lipman, M. Boguski, C. Tolstoshev, G. Schuler, E. Koonin, and D. Bassett at the NCBI for assistance in various aspects of data analysis and submission, Drs. F. Collins, D. Smith, and M. Vaudin for encouragement and support, and Dr. Sean Eddy for advice on HMMs and their uses. We are grateful to Melissa Allen, Donald Blair, Louise Bowles, Michael Holman, Michele Steptoe, Brenda Theising, and Todd Wylie for technical assistance and valuable discussion. We gratefully acknowledge the support of all staff at the Washington University Genome Sequencing Center who have contributed to this effort. The work of G.L. and C.P. was supported by the U.S. Department of Energy under contract W-7405-Eng-43. All cDNA clones are available on a cost-per-clone basis from Genome Systems (St. Louis, MO), Research Genetics (Huntsville, AL), American Type Culture Collection (Rockville, MD), United Kingdom Human Genome Mapping Project Resource Center (Hinxton, UK), and Reference Library Data Base (Berlin). Queries concerning the IMAGE consortium can be directed to info image.llnl.gov. Sequencing traces and other EST data are available at the WashU-Merck WWW site (http:// genome.wustl.edu/est/esthmpg.html). The sequence data described in this paper have been submitted to the GenBank data library.

The publication costs of this article were defrayed in part by payment of page charges. This article must therefore be hereby marked "advertisement" in accordance with 18 USC section 1734 solely to indicate this fact.

\section{REFERENCES}

Aaronson, J.S., B. Eckman, R.A. Blevins, J.A. Borkowski, J. Myerson, S. Imran, and K.O. Elliston. 1996. Toward the development of a gene index to the human genome: An assessment of the nature of high-throughput EST seqence data. Genome Res. (this issue).

Adams, M.D., J.M. Kelley, J.D. Gocayne, M. Dubnick, M.H. Polymeropoulos, H. Xiao, C.R. Merril, A. Wu, B. Olde, R.F. Moreno et al. 1991. Complementary DNA sequencing: Expressed sequence tags and human genome project. Science 252: 1651-1656.

Adams, M.D., A.R. Kerlavage, R.D. Fleischmann, R.A. Fuldner, C.J. Bult, N.H. Lee, E.F. Kirkness, K.G. Weinstock, J.D. Gocayne, O. White, et al. 1995. Initial assessment of human gene diversity and expression patterns based upon 83 million nucleotides of cDNA sequence. Nature 377: 3-17.

Altschul S.F., W. Gish, W. Miller, E.W. Myers, and D.J. Lipman. 1990. Basic local alignment search tool. J. Mol. Biol. 215: 403-410.

Bairoch, A. and B. Boeckmann. 1994. The SWISS-PROT protein sequence data bank: Current status. Nucleic Acids Res. 22: 3578-3580.

Bassett, D.E., M. Boguski, and P. Hieter. 1996. Yeast genes and human disease. Nature 379: $589-590$.

Boguski, M. and G. Schuler. 1995. Establishing a human transcript map. Nature Genet. 10: 369-371.

Bonaldo, M.F., G. Lennon, and M.R. Soares. 1996. Normalization and subtraction: Two approaches to facilitate gene discovery. Genome Res. (this issue).

Dear S. and R. Staden. 1991. A sequence assembly and editing program for efficient management of large projects. Nucleic Acids Res. 19: 3907-3911.

Dujon, B. 1996. The yeast genome project: What did we learn? Trends Genet. 12: 263-169.

Eddy, S. 1995. Multiple alignment using hidden Markov models. ISMB-95: Proceedings Third International Conference on Intelligent Systems for Molecular Biology. pp. 114-120. AAAI Press, Menlo Park, CA.

Eddy, S., G. Mitchison, and R. Durbin. 1995. Maximum discrimination hidden Markov models of sequence consensus. J. Computat. Biol. 2: 9-23.

Fulton, L.L. and R.K. Wilson. 16994. Variations on cycle sequencing. Bio-Techniques 17: 298-301. 


\section{GENERATION AND ANALYSIS OF 280,000 HUMAN ESTS}

Hawthorn L.A. and J.K. Cowell. 1996. Regional assignment of EST sequences on human chromosome 13. Cytogenet. Cell Genet. 72: 72-77.

Henikoff S. and J.G. Henikoff. 1992. Amino acid substitution matrices from protein blocks. Proc. Natl. Acad. Sci. 89: 10915-10919.

Houlgatte, R., R. Mariage-Samson, S. Duprat, A. Tessier, S. Bentolila, B. Lamy, and C. Auffray. 1995. The Genexpress Index: A resource for gene discovery and the genic map of the human genome. Genome Res. 5: $272-304$.

Johnston, M. 1996. The complete code for a eukaryotic cell. Curr. Biol. 6: 500-503.

Khan, A.S., A.S. Wilcox, and M.H. Polymeropoulos. 1992. Single pass sequencing and physical and genetic mapping of human brain cDNAs. Nature Genet. 2: 180-185.

Krogh, A., M. Brown, I.S. Mian, K. Sjoelander, and D. Haussler. 1994. Hidden Markov model in computational biology. Applications to protein modelling. J. Mol. Biol. 235: 1501-1531.

Lennon, G.G., C. Auffray, M. Polymeropoulos, and M.B. Soares. 1996. The I.M.A.G.E. Consortium: An integrated molecular analysis of genomes and their expression. Genomics 33: 151-152.

McCombie, W.R., M.D. Adams, J.M. Kelley, M.G. FitzGerald, T.R. Utterback, M. Khan, M. Dubnick, A.R. Kerlavage, J.C. Venter, and C. Fields. 1992. Caenorhabditis elegans expressed sequence tags identify gene families and potential disease gene homologues. Nature Genet. 1: 124-131.

McGuire, R.E., S.A. Jordon, V.V. Braden, G.G. Bouffard, P. Humphries, E.D. Green, and S.P. Daiger. 1996. Mapping the RP10 locus for autosomal dominant retinitis pigmentosa on 7q: Refined genetic positioning and localization within a well-defined YAC contig. Genome Res. 6: 255-266.

Matsubara, K. and K. Okubo. 1993. cDNA analysis in the human genome project. Gene 135: 265-274.

Milner, R.J. and J.G. Sutcliffe. 1983. Gene expression in rat brain. Nucleic Acids Res. 11: 5497-54520.

Newman, T. 1994. Genes galore: A summary of methods for accessing results from large-scale partial sequencing of anonymous Arabidopsis cDNA clones. Plant Physiol. 106: 1241-1255.

Pearson, W.R. and D.J. Lipman. 1988. Improved tools for biological sequence comparison. Proc. Natl. Acad. Sci. 85: 2444-2448.
Putney, S.D., W.C. Herlihy, and P. Schimmel. 1983. A new troponin $\mathrm{T}$ and cDNA clones for 13 different muscle proteins, found by shotgun sequencing. Nature

302: 718-721.

Robertson, N.G., U. Khetarpal, G.A. Gutierrez-Espeleta, F.R. Bieber, and C.C. Morton. 1994. Isolation of novel and known genes from a human fetal cochlear cDNA library using subtractive hybridization and differential screening. Genomics 23: 42-50.

Saiki, R.K., D.H. Gelfand, S. Stoffel, S.J. Scharf, R. Higuchi, G.T. Horn, K.B. Mullis, and H.A. Erlich. 1988. Primer-directed enzymatic amplification of DNA with a thermostable DNA polymerase. Science 239: 487-491.

Sambrook, J., E.F. Fritsch, and T. Maniatis. 1989. Molecular cloning: A laboratory manual, 2nd edition. Cold Spring Harbor Laboratory Press, Cold Spring Harbor, NY.

Sanger, F., A.R. Coulson, B.G. Barrell, A.J.H. Smith, and B.A. Roe. 1977. DNA sequencing with chain-terminating inhibitors. Proc. Natl. Acad. Sci. 74: 5463-5467.

Sasaki, T., J. Song, Y. Koga-Ban, E. Matsui, F. Fang, H. Higo, H. Nagasaki, M. Hori, M. Miya, E. MurayamaKayano, et al. 1994. Toward cataloguing all rice genes: Large-scale sequencing of randomly chosen rice cDNAs from a callus cDNA library. Plant J. 6: 615-624.

Soares, M.B., M.F. Bonaldo, P. Jelenc, L. Su, L. Lawton, and A. Efstratiadis. 1994. Construction and characterization of a normalized cDNA library. Proc. Natl. Acad. Sci. 91: 9228-9232.

Sonnhammer, E.L.L. and R. Durbin. 1994. A workbench for large scale sequence homology analysis. Computer Applic. Biosci. 10: 301-307.

Sonnhammer, E.L.L., S. Eddy, and R. Durbin. 1996. Pfam: A comprehensive data base of protein domain families based on seed alignments. Proteins (in press).

Sulston J., Z. Du, K. Thomas, R. Wilson, L. Hillier, R. Staden, N. Halloran, P. Green, J. Thierry-Mieg, L. Qiu, S. Dear, A. Coulson, M. Craxton, R. Durbin, M. Berks, M. Metzstein, T. Hawkins, R. Ainscough, and R. Waterston. 1992. The C. elegans sequencing project: A Beginning. Nature 356: 37-41.

Tugendreich, S., M.S. Boguski, M.S. Seldin, and P. Hieter. 1993. Linking yeast genetics to mammalian genomes: Identification and mapping of the human homolog of CDC27 via the expressed sequence tag (EST) data base. Proc. Natl. Acad. Sci. 90: 10031-10035.

Waterston, R., C. Martin, M. Craxton, C. Huynh, A. Coulson, L. Hillier, R.K. Durbin, P. Green, R. Shownkeen, N. Halloran, T. Hawkins, R. Wilson, M. Berks, Z. Du, K. Thomas, J. Thierry-Mieg, and J. Sulston. 


\section{HILLIER ET AL.}

1992. A survey of expressed genes in Caenorhabditis elegans. Nature Genet. 1: 114-123.

Wilcox, A.S., A.S. Khan, J.A. Hopkins, and J.M. Sikela. 1991. Use of 3' untranslated sequences of human cDNAs for rapid chromosome assignment and conversion to STSs: Implications for an expression map of the genome. Nucleic Acids Res. 19: 1837-1843.

Wilson, R., R. Ainscough, K. Anderson, C. Baynes, M. Berks, J. Bonfield, J. Burton, M. Connell, T. Copsey, J. Cooper, et al. 1994. The C. elegans genome project:

Contiguous nucleotide sequence of over two megabases from chromosome III. Nature 368: 32-38.

Received June 25, 1996; accepted in revised form July 29, 1996. 


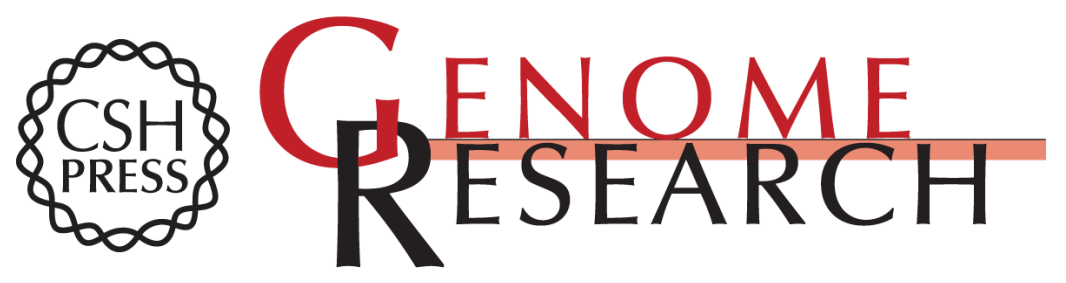

\section{Generation and analysis of 280,000 human expressed sequence tags.}

L D Hillier, G Lennon, M Becker, et al.

Genome Res. 1996 6: 807-828

Access the most recent version at doi:10.1101/gr.6.9.807

References This article cites 35 articles, 10 of which can be accessed free at:

http://genome.cshlp.org/content/6/9/807.full.html\#ref-list-1

\section{License}

Email Alerting Receive free email alerts when new articles cite this article - sign up in the box at the Service top right corner of the article or click here.

\section{Affordable, Accurate Sequencing.}

To subscribe to Genome Research go to: https://genome.cshlp.org/subscriptions 